NBER WORKING PAPER SERIES

\title{
DO OPIOIDS HELP INJURED WORKERS RECOVER AND GET BACK TO WORK? THE IMPACT OF OPIOID PRESCRIPTIONS ON DURATION OF TEMPORARY DISABILITY
}

\author{
Bogdan Savych \\ David Neumark \\ Randall Lea \\ Working Paper 24528 \\ http://www.nber.org/papers/w24528 \\ NATIONAL BUREAU OF ECONOMIC RESEARCH
1050 Massachusetts Avenue
Cambridge, MA 02138
April 2018
}

We would like to thank Richard Butler, Frank Neuhauser, John Ruser, Vennela Thumula, and Dongchun Wang for helpful feedback and comments on this work. Helpful comments were also received from many practitioners, as well as at the Association for Public Policy Analysis and Management Fall Conference and the American Economic Association Annual Meeting. Any errors or omissions remaining in this report are the responsibility of the authors. The views are our own, and do not necessarily reflect those of the Workers Compensation Research Institute. The views expressed herein are those of the authors and do not necessarily reflect the views of the National Bureau of Economic Research.

NBER working papers are circulated for discussion and comment purposes. They have not been peer-reviewed or been subject to the review by the NBER Board of Directors that accompanies official NBER publications.

(C) 2018 by Bogdan Savych, David Neumark, and Randall Lea. All rights reserved. Short sections of text, not to exceed two paragraphs, may be quoted without explicit permission provided that full credit, including $\odot$ notice, is given to the source. 
Do Opioids Help Injured Workers Recover and Get Back to Work? The Impact of Opioid Prescriptions on Duration of Temporary Disability

Bogdan Savych, David Neumark, and Randall Lea

NBER Working Paper No. 24528

April 2018

JEL No. I12,I18,J28,J38

\section{ABSTRACT}

We estimate the effect of opioid prescriptions on the duration of temporary disability benefits among workers with work-related low back injuries. We use local opioid prescribing patterns to construct an instrumental variable that generates variation in opioid prescriptions but is arguably unrelated to injury severity or other factors directly affecting disability duration. Local prescribing patterns have a strong relationship with whether injured workers receive opioid prescriptions, including longer-term prescriptions. We find that more longer-term opioid prescribing leads to considerably longer duration of temporary disability, but there is little effect of a small number of opioid prescriptions over a short period of time.

Bogdan Savych

Workers Compensation Research Institute

955 Massachusetts Ave.

Cambridge, MA 02139

bsavych@gmail.com

David Neumark

Department of Economics

University of California, Irvine

3151 Social Science Plaza

Irvine, CA 92697

and NBER

dneumark@uci.edu
Randall Lea

Alice Peck Day Memorial Hospital

Lebanon, $\mathrm{NH}$

rdlortho@aol.com 


\section{Introduction}

When used in accordance with evidence-based guidelines, opioids are an important tool for health care professionals in their quest to provide compassionate and reasoned care. However, what began as a well-intentioned effort to relieve undertreated pain has developed into an opioid crisis of epidemic proportions (U.S. Department of Health and Human Services, 2018). Aside from the direct adverse effects of opioid use and addiction, there may be important consequences for key economic outcomes. Indeed, some speculate that the rising use of opioids has contributed to the decline in U.S. labor force participation of men (Krueger, 2017).

While short-term opioid therapy can provide pain relief to some patients, the benefits of opioid therapies must be weighed against risks of addiction development, abuse, or other potential side effects (see the review in Noble et al., 2010). Evidence suggests that patients who receive multiple opioid prescriptions or patients who are prescribed large daily doses are at greater risk of experiencing overdoses (Paulozzi et al., 2012; Bohnert et al., 2011; Dunn et al., 2010; Franklin et al., 2005; Gomes et al., 2011). Opioid use is associated with nonfatal overdose hospitalizations (Coben et al., 2010), increased likelihood of emergency department visits (Braden et al., 2010), and historically has been a major cause of deaths from unintentional poisoning (Paulozzi and Annest, 2007; Paulozzi, 2012).

Opioid use is common among workers injured at work, with recent studies showing that more than half of injured workers off work for more than seven days with pain medications who did not have surgery received an opioid prescription, and many of them received opioids on a longer-term basis (Thumula et al., 2017). This raises the question about the potential impact of opioid prescriptions on outcomes that workers experience after an injury: Given the risks from opioids, are there nonetheless important benefits that might make the tradeoff worthwhile? We focus on a key potential benefit from the point of view of workers' compensation policy — the duration of temporary disability. Although some of the adverse effects of opioid use would be expected to lengthen duration of temporary disability, there could also be some benefits, via pain reduction, which enable faster return to work. To address this question, we use detailed workers' compensation claims data to examine the relationship between multiple measures of opioid prescribing and the time that injured workers spend on temporary disability benefits while recovering from an injury. 
Work-related injuries represent a substantial share of injuries that occur to working adults. Nearly half of all trauma injuries to working adults were deemed to be work-related and were covered by workers' compensation insurance, and one in five injuries for soft-tissue conditions were deemed work-related (Victor et al., 2015). This suggests that opioid medications provided in the workers' compensation system are a non-trivial part of the prescribing to which working adults are exposed.

Several studies establish a correlation between opioid prescribing and longer durations of temporary disability benefits. However, this relationship could be non-causal, driven by prescribing of opioids for more severe injuries that, independently, are associated with longer durations of disability. While past studies tried to control for injury severity, unmeasured injury severity may be correlated with both opioid prescribing and the duration of temporary disability. Moreover, opioid prescriptions may be a marker for worker characteristics that result in longer time away from work unrelated to the actual opioids, or, conversely, workers who want to return to work more quickly may choose to use opioids to speed up their return to work. Thus, a causal analysis of the effects of opioid prescriptions on the duration of disability is needed.

In this paper, we use empirical methods designed to estimate the causal effect of opioid prescriptions on the duration of disability. We rely on an instrumental variables (IV) approach that isolates the variation in individual opioid prescriptions that is driven by local prescribing patterns, rather than by individual characteristics, preferences, or decisions of workers (or their providers), such as injury severity or desire for faster return to work. This strategy assumes that local prescribing patterns influence whether an injured worker receives prescriptions for opioids, in a manner that is independent of the characteristics, preferences, or decisions of workers or their providers that directly affect the duration of disability. Our results reflect a combination of the effects opioids may have on the duration of disability because of reductions in pain as well as the potential addictive nature of opioids-effects that presumably act in opposite directions. We do not examine therapeutic, pain management effects of opioids.

The assumption underlying our identification strategy is plausible because, given the rich controls included in our models, we should account for injury severity and other sources of variation in the propensity to return to work that could otherwise be correlated with both opioid prescribing and the 
duration of temporary disability. Moreover, we present a number of supplemental analyses intended to explore threats to the validity of our IV—and these analyses closely replicate our main results. That said, one can never prove that an identifying assumption is valid, and we note possible remaining factors that could raise questions about a causal interpretation of our IV estimates. Our evidence is non-experimental, and hence how compelling this identification is rests on how one views the validity of our instrumental variables research design, and the analyses we present exploring threats to this validity. Nonetheless, if one is skeptical, our evidence is still informative about the associations between local opioid prescribing patterns and the duration of temporary disability, and raises the question of what non-causal explanation could otherwise account for the evidence.

Finally, from the point of view of the local average treatment effect interpretation of IV estimates, we believe the effect we identify off of variation in prescribing patterns is policy relevant. Presumably policymakers can shape opioid prescribing patterns through a variety of policies; we discuss some of these policies in the conclusion, although we do not yet have direct evidence of their effects on longer-term prescribing in workers' compensation.

We examine several measures of opioid prescribing, but our most important empirical results concern longer-term prescribing of opioids. We estimate the impact of opioid prescriptions on the duration of temporary disability benefits, which are received for periods when workers cannot work while recovering from injuries. The duration of temporary disability benefits is a proxy for the length of time until return to work, and it is strongly correlated with this length of time, but is not identical. However, the duration of temporary disability benefits can be measured in a very large sample available for analysis. It is the standard return-to-work measure used in research on workers' compensation, and the measure more likely to co-exist with details on workers' compensation claims such as the data we use.

Our analysis focuses on claims for which the primary diagnosis is a low back injury, for several reasons. Low back cases are quite common in the workers' compensation system, ${ }^{1}$ and prior research has

\footnotetext{
${ }^{1}$ Cases with spine sprains, strains, and non-specific pain cover between 11 and 19 percent of claims with more than seven days of lost time across states included in the CompScope ${ }^{\mathrm{TM}}$ Benchmarks studies (Table TA.8b, Dolinschi and Rothkin, 2017).
} 
highlighted higher use of opioids for low back pain claims. ${ }^{2}$ In addition, evidence-based treatment guidelines recommend against long-term use of opioids for these cases-reserving opioid prescriptions for the most severe cases and only for limited duration, ${ }^{3}$ suggesting that some of the longer-term opioid prescribing for this group of cases may be excessive. Finally, it is most straightforward to develop controls for injury severity for a narrow group of injuries.

\section{Prior Evidence on Opioid Prescribing in Workers' Compensation}

Opioids prescribing for injured workers is common and varies widely across states. Thumula et al. (2017) report that the percentage of nonsurgical claims with pain medications that had opioid prescriptions varied from just over 50 percent to over 80 percent across 26 states, with 65 to 75 percent of workers who had pain medications receiving at least one opioid prescription across most states, and 25 to 58 percent of workers who had pain medications receiving two or more opioid prescriptions. ${ }^{4}$ Longer-term prescribing of opioids is quite common. Wang (2017) found that across 26 study states, between 4 and 18 percent of workers with opioids received opioids on a longer-term basis, defined as having opioid prescriptions within the first three months after an injury and three or more filled opioid prescriptions between the 7th and 12th months after an injury (the same measure of longer-term opioids prescribing that we use). Both Thumula et al. (2017) and Wang (2017) find recent decreases in opioid prescribing among nonsurgical cases, which may be partly attributable to national, state, and local regulatory changes to combat opioid use and abuse, including mandatory use of prescription drug monitoring programs (PDMPs) by prescribers and pharmacies, adoption of guidelines for prescribing opioids, regulation of pain clinics, implementation of drug formularies, and requirements for continuing medical education on appropriate opioid prescriptions.

Many studies found longer duration of temporary disability benefits for low back pain cases with opioid prescriptions (Mahmud et al., 2000; Webster et al., 2007; Franklin et al., 2008; Volinn et al., 2009; Shraim et al., 2015). These studies typically found stronger relationships with duration of temporary

\footnotetext{
${ }^{2}$ For example, estimates in Thumula et al. (2017) show higher use of any opioids and two or more opioids for low back pain claims than in most other injury groups.

${ }^{3}$ See, for example, the discussion in Bigos et al. (1994) or Koes et al. (2001).

${ }^{4}$ Similarly, looking at cases with acute work-related low back pain in 2002-2003, Webster et al. (2009) found that the percentage of cases with opioid prescriptions within the first 15 days after an injury varied from 6 percent in Massachusetts to over 50 percent in South Carolina.
} 
disability for larger numbers of prescriptions or amounts of opioids, longer-term filling of opioid prescriptions, or more potent opioids (Schedule II versus Schedule III or IV). Similar evidence was also reported for a broader sample of workers’ compensation cases (Gross et al., 2009). However, these studies do not establish a causal link between opioid prescriptions and outcomes. Most of the studies were primarily concerned with controlling for injury severity to try to compare disability durations for similar injuries, which they did in different ways: focusing on a very narrow group of injuries (Mahmud et al., 2000); controlling for condition severity with International Classification of Diseases, 9th Revision (ICD-9) coding (Webster et al., 2007; Shraim et al., 2015); controlling for the nature of the injury, body part, and cause of injury (Swedlow et al., 2008; Gross et al., 2009); or controlling for medical severity ratings derived from detailed medical records (Franklin et al., 2008).

The central concern is that these studies do not account for correlations between unobserved characteristics of workers, opioid prescribing, and return-to-work outcomes, and hence they may generate biased estimates of the actual effects of opioids on disability duration. ${ }^{5}$

\section{Data}

Our analysis sample was derived from payment information on workers' compensation claims_the WCRI Detailed Benchmark/Evaluation (DBE) database. The DBE covers claims from national and regional insurers (including residual market carriers), state funds, and self-insured employers (from their third-party administrators). We extract data on workers, employers, injury characteristics, opioid prescriptions, and duration of temporary disability benefits. Data on opioid prescriptions and duration of benefits is based on payors' records on payments made within 24 months after an injury. ${ }^{6}$ The analysis includes workers injured between October 1, 2008, and September 30, 2013, ${ }^{7}$ in the 28 states covered in the

\footnotetext{
${ }^{5}$ Some studies directly acknowledge this problem. For example, Franklin et al. (2008) state that "the correlational nature of this study precludes the ability to draw causal inferences concerning the role of early opioid prescription. It is possible that early opioid prescription is a marker for other patient or health care provider characteristics or behaviors that might play roles in development of long-term disability” (p. 203). And Mahmud et al. (2000) state explicitly that their study only "documented associations between certain initial clinical management factors and disability duration. It was not possible to determine whether this association was causal in either direction” (p. 1,186).

${ }^{6}$ Our results are robust to using data at 12, 36, or 48 months of maturity (results available upon request).

${ }^{7}$ We define injury year 2009 (for example) as claims arising from October 1, 2008, through September 30, 2009.
} 
DBE database. ${ }^{8}$ These states represent over 80 percent of benefits paid (Sengupta et al., 2014).

Sample of Workers with Low Back Injuries

Our sample is restricted to claims for which a low back condition was a primary diagnosis code on at least two eligible physician office visits that occurred prior to invasive treatment (surgery or injection), within the first year of an injury (following Yee et al., 2015). ${ }^{9}$ The office visit criterion ensures that the sample includes workers who were diagnosed with low back injuries prior to receiving extensive treatment for such injuries, to avoid “diagnosis bias” resulting from providers selecting diagnosis codes that justify their medical treatment. We further limit our sample to cases where more than two-thirds of the office visits included a low back injury diagnosis, to increase the likelihood that our cases are predominantly low back injuries. Finally, our study is restricted to claims with more than seven days of lost time. ${ }^{10}$ About 4 percent of all claims with more than seven days of lost work time satisfied our criterion for a low back pain condition and, among these, our criterion for office visits.

\section{Opioid Prescription Measures}

Information on opioid prescriptions comes from detailed prescription transaction data collected from workers' compensation payors and their medical bill review and pharmacy benefit management vendors. ${ }^{11}$ We capture opioid prescriptions that workers filled, which were paid for by workers' compensation payors. We cannot measure whether workers take opioids, nor can we observe prescriptions filled outside the workers' compensation system. Prescription information is not available for every claim. For low back injuries with more than seven days of lost work time, about 27 percent did not have information on filled prescriptions, even though we would expect most injured workers in our sample to receive a prescription for a non-narcotic analgesic. ${ }^{12}$ Since we cannot be certain about the nature of the drug therapy when prescription

\footnotetext{
${ }^{8}$ The states are Alabama, Arkansas, Arizona, California, Connecticut, Florida, Georgia, Illinois, Indiana, Iowa, Kansas, Kentucky, Louisiana, Maryland, Massachusetts, Michigan, Minnesota, Missouri, Nevada, New Jersey, New York, North Carolina, Pennsylvania, South Carolina, Tennessee, Texas, Virginia, and Wisconsin.

${ }^{9}$ We selected cases with ICD-9-CM (International Classification of Diseases, 9th Revision, Clinical Modification) codes that were considered to be diagnoses related to the lumbar region of the spine. The diagnosis codes are available from the authors upon request.

${ }^{10}$ We impose this condition to eliminate differences across states in waiting periods for the receipt of temporary disability benefits. (Some states have waiting periods of fewer than seven days, but none have longer waiting periods.)

${ }^{11}$ For more details about the pharmaceutical data, see Thumula et al. (2017) and Wang (2017).

${ }^{12}$ We suspect that some workers in this group may have been prescribed common pain relievers that they already had in their medicine cabinet, so they did not fill a prescription at the pharmacy. Other workers may have used their group
} 
information is missing, the analysis sample includes only claims with filled prescriptions. ${ }^{13}$

We focus on longer-term opioid prescriptions, but also explore other measures, listed in the bottom panel of Table 1. Some of these claims only had non-opioid pain medications, muscle relaxants, or other non-pain medications; other claims may have received opioids for a short period of time; while other claims may have received opioids on a longer-term basis. About 71 percent of workers in our sample received at least one opioid prescription within 24 months after an injury during the study period. The other 29 percent received only prescriptions for non-opioid pain medications, prescriptions for muscle relaxants, or other non-pain medications.

Our measure of longer-term opioid prescribing captures workers who had opioid prescriptions within the first three months after an injury and later had three or more filled opioid prescriptions between the 7th and 12th months after an injury (following Wang, 2017). About 12 percent of workers with low back injuries in our sample had longer-term opioid prescriptions. Table 1 also reports the shares of workers with multiple opioid prescriptions but not longer-term prescriptions per this definition. Nearly 40 percent of workers had two or more prescriptions but not longer-term prescriptions, and 28 percent had three or more prescriptions but not longer-term opioid prescriptions.

\section{Outcome: Duration of Temporary Disability Benefits}

Our outcome is the number of weeks of temporary disability benefits that workers receive within

24 months after an injury. ${ }^{14,15}$ Workers receive temporary disability benefits while they are away from

health insurance to fill their first few prescriptions. Since we examine the sample of injured workers with a diagnosis related to the lumbar region of the spine, it is hard to imagine that these claims had no medications prescribed.

${ }^{13}$ This has two implications. First, the sample of workers with prescriptions may be skewed toward costlier and more severe cases. Second, some individuals classified as not receiving prescriptions may have received prescriptions via group health, in which case our estimated effects of opioid prescriptions would be understated if the cases without prescription information were included in the analysis sample and coded as not having opioid prescriptions.

${ }^{14}$ We calculate weeks of temporary disability benefits by dividing temporary disability payments that each worker received by the worker-specific weekly benefit rate. In fewer than 1 percent of cases, there were missing data on the wage or benefit rate, in which case we divided by the state average benefit rate.

${ }^{15}$ We collect information about both opioid prescribing and duration of temporary disability benefits over the same period of time -24 months after an injury. This raises the possibility that some workers filled opioid prescriptions after their temporary disability was over, which may raise concerns about Hill's temporality condition (Hill, 1965). However, this is unlikely to be a concern with regard to our findings. First, while it is possible that some injured workers refilled opioid prescriptions after the end of temporary disability benefits, it is unlikely that they started their opioid prescription only after the end of temporary disability. This is even less likely for longer-term prescribing-our main focus - because the average duration for workers with longer-term prescriptions was 52 weeks. Reinforcing this conclusion, we find similar results when we narrow our observation window to only 12 months after an injury. 
work recovering from an injury. The temporary disability benefits often end when workers return to work, when they are released to work by their doctor, when they reach maximum medical improvement, or when they receive permanent partial disability benefits and/or a lump-sum settlement.

Rules about how temporary disability benefits end vary across states. For instance, duration of temporary disability benefits is typically longer in states with wage-loss benefit systems since these states do not shift workers to permanent partial disability payments when workers achieve permanency in their condition, but instead workers often continue receiving temporary disability benefits. ${ }^{16}$ We therefore compare duration of temporary disability within each state, where the same rules and procedures for determining temporary disability benefits apply; we do this by estimating models with state fixed effects.

The duration of temporary disability benefits does not exactly reflect the duration of time that workers were away from work. For example, temporary disability benefits may end when workers start receiving permanent partial disability benefits or when workers choose to settle their claim. In some states, temporary disability benefits may be terminated while workers resolve disputes about ability to return to work or disputes about their remaining impairment. ${ }^{17}$ Finally, the ultimate duration of time off work may not be observed for claims that remain open.

\section{Other Controls}

We control for a rich set of covariates that could affect the duration of temporary disability benefits. For example, older workers are less likely to return to work, and workers in some industries (such as construction) may have unique return-to-work problems (Galizzi and Boden, 1996). We include the following worker controls in our regression models: age, gender, marital status, tenure at the time of injury, and preinjury wages. Workplace characteristics include firm’s payroll size and dummy variables

Finally, if opioid prescriptions help workers improve return to work, it would be inappropriate to exclude from the analysis prescriptions that happened after the end of disability.

${ }^{16}$ In wage-loss systems, the benefit rate reflects the difference between current earnings and what workers earned before their injury.

${ }^{17}$ We exclude from our sample cases with no temporary disability benefits that later received permanent partial disability/lump-sum payments. These cases are likely disputes about compensability that were later paid as a lumpsum settlement. We also exclude from the sample fewer than 1 percent of cases where the number of weeks of temporary disability duration was unreasonably high, i.e., greater than the 104 weeks that we can expect with 24 months of maturity data. 
distinguishing industries and occupations based on injury risk. ${ }^{18}$

Characteristics of the local labor market may also affect how long workers stay out of work. We control for the county unemployment rate ${ }^{19}$ and residence in a rural zip code. ${ }^{20}$ We also control for two other characteristics of the population that may affect ability to work - the percentage of residents with less than a high school degree at the Primary Care Service Area (PCSA) level, ${ }^{21}$ and the percentage of residents who were disabled at the county level. ${ }^{22}$

We developed controls for injury severity specific to the low back conditions we study. ${ }^{23}$ Our controls categorize injury severity based on the diagnosis and the treatment that workers received. For surgical cases, we developed a severity scoring system based on the intensity and extent of treatment that workers received. This improves on approaches in prior studies that controlled for nature of injury, body part, and cause of injury (Swedlow et al., 2008; Gross et al., 2009), or controlled for broad categories of condition severity reflected in ICD-9 coding (Webster et al., 2007; Shraim et al., 2015).

The idea behind our approach is that the extent of surgical intervention reflects the potential severity of the injury that workers experience-more extensive procedures may reveal more severe injuries. Taking into account medical bill level information about medical procedures and diagnostic codes, our scoring system assigns points based on different types of surgical procedures (discectomy/decompression, fusion, or both); number of levels operated on (one, two, or more than two); and number of procedures

\footnotetext{
${ }^{18}$ These include high-risk services, low-risk services, clerical/professional occupations (regardless of industry), manufacturing, construction, trade, and other industries (see Dolinschi and Rothkin, 2017).

${ }^{19}$ We use the U.S. Bureau of Labor Statistics' Local Area Unemployment Statistics (LAUS); see https://www.bls.gov/lau/.

${ }^{20}$ We use the ZIP code Rural-Urban Commuting Areas (RUCAs) geographic taxonomy; see https://ruralhealth.und.edu/ruca.

${ }^{21}$ Less-educated workers likely face many fewer jobs for which they are qualified.

${ }^{22}$ These last two measures are derived from Area Resource Files. The zip code to PCSA crosswalks used to construct our data were obtained from The Dartmouth Atlas, which is funded by the Robert Wood Johnson Foundation and the Dartmouth Clinical and Translational Science Institute, under award number UL1TR001086 from the National Center for Advancing Translational Sciences (NCATS) of the National Institutes of Health (NIH). See http://www.dartmouthatlas.org/downloads/pcsa/zip5_pcsav31.dbf. The Area Resource Files are based on data from the 2010-2014 American Community Survey (ACS) Summary File.

${ }^{23}$ We rely on these severity controls to avoid pitfalls from using ICD-9 based controls from administrative records for subgroups of low back pain injuries, which may arise due miscoding or diagnosis-related group "creep” (Guller, 2006). Prior studies showed that using ICD-9 based groups to characterize spinal disorders was unreliable when studying outcomes (Faciszewski et al., 1995, 1997, 2003), potentially reflecting lack of consistency in diagnosis coding for spine conditions. Nonetheless, results from sensitivity tests with controls for ICD-9 based low-back pain injury groups were not materially different from the estimates we report.
} 
(one, two, or more than two). This measure ranges from zero to nine points, with more complex treatments having a larger number of points. ${ }^{24}$ Nonsurgical cases have zero points, but have separate controls for a three-way classification based on intensity of treatments: cases with medications only; cases with medications and physical therapy only; and cases with medications, physical therapy, and injections. ${ }^{25}$ The use of separate controls for surgical and nonsurgical severity is equivalent to interacting severity controls with surgery and non-surgery indicator variables. We also control for whether there was a surgery or an early MRI.

\section{Methods}

We specify the relationship between duration of temporary disability and opioid prescriptions measures as:

$$
\log \left(\mathrm{Y}_{i j s t}\right)=\alpha+\beta \cdot \mathrm{OPSCRIP}_{i j s t}+\mathrm{X}_{i j s t} \delta+\mathrm{YR}_{t} \lambda+\mathrm{ST}_{s} \gamma+\varepsilon_{i j s t}
$$

$\mathrm{Y}_{\mathrm{ijst}}$ is duration of temporary disability for worker $i$, in area $j$ of state $s$, in year $t .{ }^{26}$ OPSCRIP $_{i j s t}$ is the opioid measure of interest. $X_{i j s t}$ is a vector of control variables. $\mathrm{YR}_{t}$ is a vector of year fixed effects, and $\mathrm{ST}_{s}$ is a vector of state fixed effects. To be clear, we are estimating the effect of opioid prescriptions relative to treatments that do not involve opioid prescriptions (or, in some specifications, receive either no or shorter-term prescriptions), which of course can include other, non-opioid prescriptions.

We first estimate equation (1) using ordinary least squares (OLS). This approach provides descriptive evidence on the associations between opioid prescriptions and duration of temporary disability. However, these associations may reflect unobserved worker and/or injury characteristics that are correlated with both opioid prescriptions and duration. We think there are most likely two kinds of unmeasured characteristics of workers/injuries that can lead to biased estimates of the causal effects of opioid prescriptions. First, opioid prescriptions can be associated with unmeasured differences in injury severity that directly affect duration of temporary disability benefits, leading the OLS estimate of $\beta$ to overstate the

\footnotetext{
${ }^{24}$ More details on the construction of this measure is available from the authors upon request. We verified that the results were insensitive to introducing separate dummy variables for each value of this measure.

${ }^{25}$ The third group also includes about 3 percent of cases with injections that did not have physical therapy services.

${ }^{26}$ The $j$ index is explained below.
} 
extent to which opioid prescriptions inhibit return to work (increase the duration of disability). ${ }^{27}$ Second, opioid prescriptions can be associated with unmeasured differences in propensity to return to work quickly. We do not know, a priori, the direction of this association and hence the direction of bias from this unmeasured propensity. If, for example, workers who have a higher propensity to return to work are also more likely to fill opioid prescriptions (conditional on the other controls), because they use opioids to help ease return to work, then OLS estimates can understate the negative effect of opioids on duration of disability. Alternatively, workers less prone to return to work after an injury may seek opioid prescriptions, in which case the bias would overstate the extent to which opioid prescriptions inhibit return to work.

\section{Instrumental Variable Approach}

Our IV approach attempts to purge the estimates of the impact of unmeasured injury severity or propensity to return to work and, hence, to obtain unbiased (formally, consistent) estimates of the causal effects of opioid prescriptions. ${ }^{28}$ This approach requires an exogenous source of variation that affects opioid prescriptions but does not affect temporary disability duration except via its influence on prescriptions. Our IV is local area prescribing patterns (OPLOCAL) ${ }^{29}$ For each individual observation we determine local area prescribing rates based on low back cases in an area (indexed by $j$ ). The opioid prescription rate for injured worker $i$ in area $j$ (in state $s$ ) in year $t$ is based on all workers in area $j$, excluding individual $i$ (we denote the number of observations in area $j$ (in state $s$ and year $t$ ) as $\mathrm{N}_{j s t}$ ). Thus,

\footnotetext{
${ }^{27}$ While we believe we improve on the measures of injury severity used in past studies, we cannot be sure that our measures fully capture injury severity.

${ }^{28}$ We use two-stage least squares (2SLS). We do not estimate duration models that are sometimes used to examine spells of time away from work that are not fully observed (censored). Instrumental variables approaches are considerably more complicated with duration data that could be censored (e.g., Bijwaard, 2009). Our results are not sensitive to potential censoring concerns; the results change little when we use duration of temporary disability measured at 36 or 48 months after an injury. Since we use a natural logarithm of temporary disability duration, our approach (in the absence of censoring) is essentially a log-linear model that can be interpreted as a proportional hazard model with a constant hazard for leaving disability (shifted by the independent variables).

${ }^{29}$ There is another potential reason to be concerned about obtaining spurious evidence of a causal effect of longerterm opioids prescriptions from OLS estimation of equation (1). There could be a somewhat mechanical relationship between long disability durations and longer-term opioids prescriptions because longer-term prescriptions are less likely to be written when temporary disability ends quickly. In fact, the relationship is not this deterministic. For example, in our sample about 11 percent of workers with longer-term opioid prescriptions had durations of less than 11 weeks, and about 20 percent had durations of less than 20 weeks. Conversely, 7 percent of workers without any opioid prescriptions had durations of temporary disability exceeding 40 weeks. Of course, the IV approach addresses this concern; there is no reason the HRR-level of long-term opioid prescribing would be mechanically or deterministically associated with long duration of temporary disability for an individual.
} 
the formula for OPLOCALijst is

$$
\text { OPLOCAL }_{i j s t}=\frac{\sum_{i^{\prime} \neq j} \text { OPSCRIP }_{i^{\prime} j s t}}{\mathrm{~N}_{j s t}-1} \cdot{ }^{30,31}
$$

It is typical to interpret IV estimates as local average treatment effects that put the most weight on effects for those whose opioid prescription variation is driven by variation in the local prescription patterns (the “compliers”). In our view, this is a strength of the IV that we use, because variation in prescribing patterns across areas is the type of variation that policymakers seem likely to be able to influence via policies regulating prescriptions of opioids in workers' compensation cases. We discuss examples of these policies below when we interpret our estimates.

We define local areas using Hospital Referral Regions (HRRs) developed by the Dartmouth Atlas. ${ }^{32}$ We use HRRs as the geographic unit for defining prescribing patterns because they provide a high percentage of within-area prescriptions relative to other possible geographic measures we could use, while allowing for variability in prescriptions across parts of the state. About 74 percent of filled prescriptions for opioids were prescribed by physicians with offices in the same HRR as the worker's residence (and another 14 percent were in a different HRR in the same state). Other definitions of geographic areas, such as CBSAs, produced considerably lower percentages of prescriptions that were prescribed within the same area as workers' residences. We only use observations that are in areas with at least 15 observations within each HRR and year combination for creating the IV. Our sample of states includes 219 HRRs, some of which cross state lines. Given that we exploit variation in opioids prescribing rates at the HRR level, all standard errors we report are clustered at the HRR level.

\footnotetext{
${ }^{30}$ Excluding individual $i$ from this estimation avoids creating a mechanical correlation between the instrument and individual opioid prescriptions — variation that would not be purged of unmeasured injury severity or propensity to return to work.

${ }^{31}$ Note that OPLOCALijst is based on the observed surgical and nonsurgical mix of cases. We want the prescribing pattern measure to reflect only the variation in prescriptions for the same kind of treatment, so that it should also reflect the case mix. We use the same definition of opioid prescriptions (listed in Table 1) for both OPSCRIP and OPLOCAL, depending on the opioid prescribing measure for which we are estimating the specification.

32 These areas are determined based on use of medical services by Medicare patients. The Dartmouth Atlas divides the United States into 3,436 distinct hospital service areas (HSAs); the areas are defined so that Medicare patients living in an HSA get the majority of their health care from hospitals within the area. These areas are then grouped into 306 HRRs. For each claim, we determined the HRR from the zip code associated with the claim, based on the worker's zip code of residence. When an injured worker's zip code of residence was missing, we used the zip code of the injured worker's employer. If both of those zip codes were missing, we used the zip code of the first physician office visit for the injured worker. If all three were missing, we used the zip code in which the injury occurred.
} 
Opioid prescribing patterns at the HRR level vary—often dramatically—within states. Figure 1 provides information on the distribution of longer-term opioid prescribing rates for our analysis sample. The figure displays the minimum, maximum, and average across HRRs for each state in our sample. We observe substantial variation in the rates of longer-term opioid prescribing both across and within across states. For example, areas with the highest rates of longer-term opioid prescriptions within each state had, on average, 30 percentage point higher rates of longer-term opioids than areas with the lowest prescribing rates.

\section{Instrument Validity}

One condition for the validity of the instrument is that it strongly predicts whether workers received opioids (i.e., instrument relevance). We present evidence of strong predictive power of the IV below. The second condition for a valid instrument is that the IV is not correlated with unobserved claim or claimant characteristics that affect the duration of disability (such as unobserved injury severity or propensity for return to work), conditional on the controls. We cannot directly test this exclusion restriction. We do, however, present a number of analyses below that bolster this assumption, but we cannot, of course, prove that the exclusion restriction holds.

Variation in the instrument reflects prescribing patterns for all other workers (excluding the individual) within the same HRR with low back injuries, which should be driven by the treatment patterns followed by doctors within the local area, for other patients. It seems unlikely that prescription patterns for other workers in the same local area would be correlated with an individual worker's duration of disability, conditional on their own opioid prescriptions. Nonetheless, there are possible reasons the exclusion restriction could be violated. In principle, workers could somehow be sorted across high- and lowprescription areas in a way that generates a correlation between prescribing patterns and unobserved injury severity or propensity for return to work. However, this seems unlikely given our extensive controls. For example, although particular areas could have overrepresentation of specific industries and, hence, injuries that are correlated with both prescribing patterns and the duration of disability, we control for industry and injury severity. Some areas may have an older workforce, and age could influence both prescribing patterns and the duration of disability, but we control for workers' ages. Moreover, none of these possibilities 
explain why local prescribing patterns should matter once we condition on the individual worker's opioid prescriptions.

Yet another dimension of sorting is the local variation in surgery rates for similar industries, workers, etc. But we control for treatment variation and the case mix. Local labor market conditions could also matter. For example, weak labor markets could create longer disability durations and perhaps also be associated with more opioid use or abuse. To address this, we control for county-level unemployment rates and the percentage of workers with less than a high school education. There could also be regional variation in comorbidities that affect disability durations and are correlated with opioid prescriptions. But this should be accounted for by our control for county-level variation in the percentage of disabled workers.

It is possible, in principle, that workers strategically move to HRRs with higher rates of opioid prescriptions when they are more likely to use (or want to use) opioids. But this source of mobility appears unlikely given the size of the local areas that we chose for our analysis.

A potentially more challenging possibility is that workers with a greater need for opioids may gravitate to the high-prescribing doctors within an HRR. This would result in higher average prescribing rates in areas where workers want to use a lot of opioids (even if the distribution of doctors by "innate" prescribing rates—i.e., what we would observe, hypothetically, prior to this sorting —is the same in each HRR). We address this concern by exploring variation in prescribing patterns measured at the physician level rather than the worker level. In particular, we give each provider in an area equal weight when constructing local area prescribing rates to avoid, say, inflating the local prescribing pattern in HRRs where, over the course of treatment, workers gravitate to high-prescribing providers. We show, below, that our results are robust to this alternative specification of the IV (and to using another closely related approach). We believe that this additional evidence indicates that doctor shopping does not drive the results. However, we cannot rule out the possibility that doctor shopping is reflected in the first provider a worker visits - perhaps based on a priori information from other workers about which providers are more likely to write opioid prescriptions. Thus, while our evidence makes it less likely that doctor shopping drives our results and renders our estimates non-causal, we cannot decisively rule this out.

Another potential issue that could undermine the validity of the IV is if physicians who prescribe 
opioids also use other practices that lead to longer durations of disability. We cannot rule this possibility out, although we think this problem is likely minor. First, if we were just using physician-level prescribing as the IV, the IV could well be correlated with other physician practices. However, we are using HRR-level prescription variation, and there is less reason to believe that individual-level treatment (aside from opioid prescribing) varies with HRR-level opioid prescribing. Second, variation in other practices that is correlated with opioid prescribing is not problematic if the other practices are ultimately driven by opioid prescribing behavior. In that case, accounting for these other physician practices would be overcontrolling (controlling for variation in opioid prescribing). Third, we control for surgery—a key difference in practice—and also estimate separate models for surgical and non-surgical cases. Finally, we suspect that physician practices have more to do with short-term rather than longer-term opioid prescriptions, and our key findings concern longer-term prescriptions. ${ }^{33}$

\section{The Effects of Opioid Prescriptions}

\section{Descriptive Statistics}

Table 1 provides descriptive statistics on opioid prescriptions and claim outcomes, for various measures of opioid prescriptions: whether workers had any opioid prescriptions in the 24 months after an injury, the number of opioid prescriptions excluding longer-term use, and longer-term prescribing of opioids. The first row shows that the average duration of temporary disability benefits was about 15 weeks longer for claims where workers had any opioid prescriptions. The differences were still large, although less pronounced in absolute terms, for median duration.

Columns (4)-(7) indicate that the differences in measures of temporary disability duration were driven primarily by workers with multiple opioid prescriptions, and more so by workers with longer-term opioid prescriptions. Looking first at prescription counts and excluding longer-term use, we observe a relatively small difference in duration (1 week) between workers with one prescription and workers with no prescriptions. Workers with two prescriptions had 6 weeks longer duration (about a 50 percent difference), and workers with three or more prescriptions had nearly 20 weeks longer duration (almost three times the

\footnotetext{
${ }^{33}$ Schnell and Currie (2017) document that doctors from higher-ranked medical schools, in the same specialty, etc., write fewer opioid prescriptions by provider, but do not have data on number of prescriptions per patient.
} 
duration of workers with no prescriptions). However, we find much longer duration of temporary disability for those with longer-term opioids, for whom average duration was nearly a year (51.6 weeks). These statistics imply that it is important to separately examine the effects of more-intensive prescribing of opioids, and not just any opioid prescriptions versus no opioid prescriptions. ${ }^{34}$

The lower panel of Table 1 reports additional information on opioid prescriptions, including the distribution of observations by number of prescriptions and longer-term prescribing. The last two columns show that outcomes and opioid prescribing varied substantially between surgical and nonsurgical cases. Surgical cases had longer duration of temporary disability benefits (51 weeks, versus 19 weeks for nonsurgical cases). Surgery is also strongly associated with opioid prescriptions—95 percent of surgical cases had at least one prescription, and one-third of workers with surgeries had longer-term opioid prescriptions. This difference is why we control in our models for whether a case is surgical or nonsurgical, and let the local prescribing patterns reflect the surgical/nonsurgical mix at the HRR level. We also take this one step further and estimate separate models for the two types of cases.

\section{Effects of Opioid Prescriptions on Duration of Temporary Disability: OLS Estimates}

Table 2 reports OLS estimates that adjust for differences between claims based on characteristics of workers, employers, injuries, and workers’ compensation systems. We show estimates using an increasingly detailed set of controls. Specification 4 provides the most compelling evidence among the OLS regressions, as it includes the controls for injury severity, worker characteristics, workplaces, and location. Comparing the estimates for the prior specifications is informative about the partial correlations among disability duration, opioid prescriptions, and the control variables. Since we estimate models for log duration, the estimates approximately reflect the percentage change in the duration of temporary disability for a one-unit change in the independent variables, although the approximation can be far from exact for the kinds of large estimates we obtain here. For example, the estimate of 84.8 in the first column (Specification 1) implies that the duration of temporary disability benefits was 133.5 percent higher when workers had at least one opioid prescription than when workers had no opioid prescriptions (base category),

\footnotetext{
${ }^{34}$ Workers with only one prescription may include many workers who filled prescriptions but did not use them, or who used them short-term but quickly curtailed their use.
} 
for otherwise comparable claims, as shown in the second row of the table. ${ }^{35}$ The estimates in Table 2 closely parallel what has been done in past research on opioid prescribing and duration of disability.

While the estimates in Table 2 consistently point to a positive correlation between any opioid prescriptions and duration of temporary disability benefits, conditional on the controls, the estimates are sensitive to which controls we include. Going from Specification 1, with the fewest controls, to Specifications 3 and 4, with the most controls, reduces the strength of the positive relationship between any opioid prescriptions and duration of disability by about two-thirds (in terms of the percentage effect). Yet the association remains positive and strongly statistically significant; in Specification 4, with all the controls, we estimate that workers with any opioid prescriptions had a 42.9 percent longer duration of temporary disability benefits than workers without opioid prescriptions. Given the mean duration of 11.3 weeks for workers with no opioids (Table 1), this is an increase of about 4.8 weeks. The table also shows that workers with more severe injuries had long disability durations, as we would expect, and were also more likely to receive opioids, so controlling for severity reduces the association between any opioid prescriptions and disability duration. ${ }^{36}$

\section{The Role of Local Prescribing Patterns}

Before turning to the IV results, we present estimates of our first-stage regressions relating opioid prescriptions at the individual level to local prescribing patterns — which provide our instrumental variables. The predictive power of local prescribing patterns has to be strong for the empirical strategy to be informative about the true effects of opioid prescribing patterns on duration of disability.

\footnotetext{
${ }^{35}$ Note that we have multiplied the estimated coefficients by 100 to express them as percentages. The 0.848 coefficient estimate, when multiplied by 100, provides an approximate percentage effect (84.8), but this approximation is much more accurate for smaller estimates. A more precise estimate of the percentage change comes from taking the coefficients reported in the table (from equation (1), $\beta \cdot$ OPSCRIP), and computing $100 \cdot\{\exp (\beta$ -OPSCRIP/100)-1\}; using this calculation, the 84.8 estimate, for example, implies a 133.5 percent change. The standard error of the implied percentage effect (not reported, but used to compute significance levels) is computed from a first-order approximation to this function using the Delta method. The table also reports estimated coefficients for some of the controls; full model estimates are available from the authors upon request.

${ }^{36}$ The injury severity measures are strongly correlated with the duration of temporary disability benefits. For instance, for surgical cases, one additional point (one extra modality during a surgery) on the severity score is associated with 12 percent longer duration of temporary disability benefits. For nonsurgical cases, we found that cases that had medications and physical therapy services only, when compared with cases with only medications, had much longer duration of temporary disability. Nonsurgical cases that had medications, physical therapy, and injections had far longer duration of temporary disability benefits than nonsurgical cases with only drugs.
} 
Table 3 provides estimates from the first-stage regressions, including the full set of controls from Specification 4 in Table 2. The evidence indicates - in the first panel of the table-that the IV passes this test for the estimation of the effect of receiving any opioid prescriptions. The estimate implies that a 10 percentage point increase in the local area opioid prescribing rate of any opioids is associated with a 3.4 percentage point higher likelihood that injured workers with low back injuries will have any opioid prescriptions. ${ }^{37}$ The F-statistic on the first-stage regression is very large (107).

The remaining panels of the table report estimates of first-stage models for the different measures of opioid prescriptions we use in subsequent analyses. Each case uses the local prescribing pattern that corresponds to the individual-level prescription measure. We find that, regardless of the definition of opioid prescribing, local prescribing patterns are strongly predictive of individual prescription patterns, with injured workers in areas with higher prescribing rates significantly more likely to receive opioid prescriptions.

Note that the results in Table 3, in addition to helping validate our research method, provide interesting information on the extent to which opioid prescriptions vary across local markets, even for workers with the same measured injury severity, surgical mix, etc. We do not claim to know all of the sources of variation in prescribing patterns across HRRs. But we would suggest that this variation points to differences in prescribing behavior that can be shaped by workers' compensation policy and opioids policy more generally. And the strong relationships between local prescribing patterns and individual opioid prescribing imply that policy-induced reductions in prescribing in high-prescription areas could substantially reduce opioid prescriptions. Effects of Opioid Prescriptions on Duration of Temporary Disability: Instrumental Variable Estimates

Panel A of Table 4 presents the 2SLS estimates of the effect of any opioid prescriptions and provides a comparison with the OLS estimates from Table 2. Again, we use specifications including the

\footnotetext{
${ }^{37}$ The local prescribing pattern is measured as a proportion from zero to one, and the dependent variable is either zero or one, so that a 10 percentage point increase in the local prescribing pattern has an effect on the probability of any opioid prescription equal to one-tenth of the estimated coefficient. Prior studies suggest that physicians play an important role in shaping opioid prescribing patterns. For instance, Barnett et al. (2017) documented large differences in opioid prescribing patterns across physicians even within the same hospital. As noted earlier, Schnell and Currie (2017) also documented that physicians' education is strongly associated with opioid prescription patterns.
} 
full set of controls from Specification 4 in Table $2 .^{38}$

Once we correct for the endogeneity of prescriptions or correlations with unobserved injury severity, we find little evidence of a relationship between whether a worker received any opioid prescriptions and duration of temporary disability. The 2SLS estimate (4.5) is close to zero and statistically insignificant. Although the estimates in Panel A of Table 4 suggest that opioid prescriptions do not lead to longer duration of disability, the specification based on any opioid prescriptions combines effects of shortterm use (only one prescription) and multiple prescriptions or longer-term prescriptions. Thus, we next explore the effects of opioid prescriptions using different ways to characterize prescriptions. After discussing this more complete set of results, we will return to the issue of interpreting differences between the OLS and 2SLS estimates.

Since the analysis in Tables 2 and 4 is based on one or more opioid prescriptions, we first turn to examining how the results change if we estimate, instead, the effect of having two or more, or three or more, opioid prescriptions. Both OLS and 2SLS estimates for these specifications are reported in Panel B of Table 4, again for the specification including the full set of controls. The 2SLS estimates in Panel B suggest that the impact of opioids varies with the number of prescriptions that workers filled. Cases with three or more prescriptions, when compared with cases with no prescriptions, had longer duration of temporary disability benefits, by 52 percent. This evidence, coupled with the weaker evidence of an effect for two or more versus no prescriptions (a statistically insignificant 20.2 percent longer duration), suggests that the results for any opioids in Panel A hide substantial differences across different numbers of prescriptions, and that the effect of opioids on disability duration may arise only for workers with multiple prescriptions.

In Panel C, we report estimates for similar specifications, but now excluding from the set of observations those who had longer-term prescriptions, as defined earlier. In this case, we no longer find evidence of an effect of multiple opioid prescriptions on the duration of disability; the estimated coefficients are closer to zero and not statistically significant.

\footnotetext{
${ }^{38}$ We report only the estimated coefficients of the opioid prescribing variable; full model estimates are available upon request.
} 
The differences between the results in Panels B and C of Table 4 suggest that it is longer-term opioid prescriptions that are responsible for longer durations of temporary disability. Panel D provides direct evidence of this, showing model estimates where we now characterize workers by whether they had longer-term opioid prescriptions. The 2SLS estimates in Panel D point to a strong effect of longer-term opioid prescribing on the duration of temporary disability benefits; workers with longer-term opioid prescriptions had durations of temporary disability that were 251 percent longer-or more than triple the duration of similar workers, with similar injuries, without opioid prescriptions.

\section{Interpreting the Magnitudes}

Our empirical analysis is intended to estimate the causal effects of opioid prescriptions. One can interpret the individual-level estimates as the effect of a policy change that eliminated, for example, longerterm opioid prescriptions. However, from a policy perspective we might ask a different question: What is a reasonable expectation for the reduction in opioids that policy could bring about, and if it did so, how much would we expect the duration of temporary disability benefits to fall?

To get a handle on this question, consider a 5 percentage point decrease in longer-term opioid prescriptions among workers with low back injuries, from an average of 12 percent to 7 percent of cases (Table 1). This 5 percentage point decrease is a plausible policy effect, based on prior evidence that, after the implementation of Kentucky House Bill 1, the percentage of claims with pain medications that had any opioids decreased 10 percentage points, and the percentage of claims with pain medications that had two or more opioid prescriptions decreased 6 percentage points (Thumula, 2017). ${ }^{39}$ Based on the 2SLS estimate in Panel D of Table 4, this change translates to a 12.6 percent decrease in the duration of temporary disability, or 2.8 weeks shorter average duration of temporary disability for workers with low back injuries.

\section{Bias in OLS Estimates}

In Panels A-C of Table 4, the 2SLS estimate is smaller than the OLS estimate, suggesting that OLS provides an upward-biased estimate of the effect of opioid prescriptions on duration of disability. The most

\footnotetext{
${ }^{39}$ Kentucky House Bill 1 aimed to reduce opioid prescriptions by requiring prescribers to check the prescription drug monitoring database prior to prescribing opioids, establishing standards for opioid prescriptions, and implementing mandatory educational and patient treatment practices. The Thumula study did not present evidence on changes in longer-term opioid prescribing.
} 
plausible reason for upward bias, in our view, is failure of the severity controls to fully capture differences in severity, in which case a positive relationship between opioids and unmeasured severity would overstate the causal effect of opioid prescriptions. In contrast, the IV estimates using only the variation in prescribing patterns across HRRs would break the link between unmeasured severity and opioid prescriptions and, hence, eliminate the positive bias.

In contrast, in Panel D of Table 4 the 2SLS estimate of the effect of longer-term opioid prescriptions is larger, although not statistically significantly so, than the OLS estimate. This suggests that there is another factor at work that biases the OLS estimate downward. Our conjecture is that the other factor in this case is that some workers who want to return to work use opioids longer-term to enable them to do so, and ignoring this “endogenous” choice to use opioids longer-term obscures part of the causal effect of longer-term opioid prescriptions in increasing the duration of disability. This interpretation does not mean that, overall, longer-term opioids enable return to work. Rather, it just means that for some workers this mechanism is active. The 2SLS estimates imply that, on the whole, longer-term opioids lead to substantially longer duration of temporary disability. There is no contradiction between different findings for bias in the OLS estimates for longer-term prescriptions of opioids vs. short-term, limited prescriptions. Short-term prescriptions may simply reflect unmeasured injury or treatment differences, while longer-term prescriptions may be associated with behavioral differences.

\section{Effects Relative to Broader Comparison Groups}

The main analyses just presented compare disability durations for those receiving two or more, three or more, or longer-term opioid prescriptions relative to no opioid prescriptions. We view these estimates as more comparable to each other since the untreated group remains the same. However, it is possible that as we change the treated group to those with more or longer-term opioid prescriptions, they become less comparable to those getting no prescriptions. Therefore, in Table 5 we report estimates where the comparison is simply to those getting fewer prescriptions - e.g., 3 or more vs. 0 , 1 , or 2 prescriptions, or longer-term opioid prescriptions vs. cases without longer-term opioid prescriptions (which includes any other prescriptions). The results are qualitatively very similar. The 2SLS estimate for longer-term prescriptions is larger, and, presumably because the distinction between the two groups is less sharp, less 
precise (reflected also in a somewhat weaker but still strong first stage; compare to Table 3). The larger estimate could just reflect greater imprecision. Alternatively, it may reflect the fact that workers who receive shorter-term but not longer-term opioid prescriptions (who are omitted from the untreated group in Table 4) have shorter disability durations as a result (i.e., causally) - consistent with the negative 2SLS point estimates for multiple but not longer-term opioid prescriptions.

\section{Heterogenous Effects}

The relationship between opioid prescriptions and duration of temporary disability may differ between surgical and nonsurgical cases, perhaps because the same intensity of opioids may be more medically-indicated for the same diagnosis in surgical cases than nonsurgical cases. The results for nonsurgical cases are very similar to the full-sample results, as shown in Table $6 .{ }^{40}$ We could not learn much about the much smaller number of surgical cases (a bit over 10 percent of cases) using our strategy, as the prescribing patterns IV did not strongly predict opioid prescriptions for this subset of cases.

Moreover, it is not meaningful to examine the relationship between any opioids and duration of temporary disability benefits for surgical cases since nearly all surgical cases receive some opioids.

\section{Robustness of Estimates}

We conducted several checks examining whether the results are sensitive to different definitions of the dependent variable, to changes in the sample definitions, or alternative ways of constructing the IV that address potential challenges to the validity of the instrument. ${ }^{41}$ As we noted earlier, our results are robust to using cost measures derived at different maturities. We continued to find a large, positive, and statistically significant effect of longer-term opioid prescriptions across claims with different maturities (12, 36, and 48 months), with all the estimates showing an approximate doubling to tripling of duration. This evidence implies that our findings are not influenced by open claims.

We find similar percentage effects from using linear rather than log specifications for the duration of temporary disability benefits. Our main results are also robust to changing the threshold size of the local

\footnotetext{
${ }^{40}$ We do not show all of the estimates from the previous tables. We show results for any prescriptions, two/three or more prescriptions excluding longer-term prescriptions, and longer-term prescriptions.

${ }^{41}$ We summarize some of the robustness checks here, and report what we view as the most important results; full estimates are available from the authors upon request.
} 
areas that we use for estimating local practice patterns. ${ }^{42}$

In our main analyses, we limit the sample to primarily cases with a low back pain diagnosis. An alternative sample specification is to relax some of the constraints imposed on the data. In particular, we explored the sensitivity of our estimates to the sample that no longer excludes cases where less than twothirds of the office visits were for a low back pain diagnosis. We find that our pattern of results described in the main specifications holds with this change in the sample. While the cases included in this analysis are more heterogeneous, the precision of the estimates increases owing to the larger samples.

\section{Validity of the Instrument}

We conducted a number of analyses that consider potential threats to the validity of our IV. First, in our main specifications we used state fixed effects to control for state-specific factors that are constant over the period of the study, such as time-invariant state-specific workers' compensation system features. An alternative approach is to control for state fixed effects interacted with year fixed effects, which will also capture state-specific workers' compensation policies (or other factors) that change over time. In this specification, the impact of opioids is estimated from the variation in opioid prescriptions within each year of data for each state. Because adding state-by-year interactions potentially eliminates a good deal of identifying information — in particular, changes in opioid prescribing over time that are common to HRRs in a state-we might obtain much less precise 2SLS estimates.

Adding state-by-year fixed effects is most important if there are important determinants of the duration of temporary disability that vary by state and year, that are correlated with opioids prescribing, and that are not captured in our controls. We already control for time-varying local labor market conditions. And there is not much variation in workers' compensation policies in our sample period. Moreover, there may be some policy variation that is useful as it could potentially drive variation in opioid prescribingsuch as policies on adoption and enforcement of prescription drug monitoring programs, rules about dispensing of Schedule II or III prescriptions, and other limits on opioid prescriptions. We would not want to control for policy variation that generates exogenous variation in prescribing patterns across states and

\footnotetext{
${ }^{42}$ This refers to either increasing or decreasing the minimum number of claims in an HRR to estimate the prescribing pattern—a minimum we imposed to increase the precision of the estimate.
} 
years. That is why our preferred specifications are those with separate state and year fixed effects.

Table 7 provides coefficient estimates from our regressions for the original specifications, and the alternative specifications that control for state-year specific fixed effects. The results are considerably less precise, as expected — and we find a somewhat smaller effect of longer-term opioid prescriptions (that is no longer statistically significant). However, the sign pattern of the estimates is the same, and, for longer-term opioids, the point estimate of 89.9 still implies very large effects (approximately 146 percent longer duration), and would still be statistically significant based on the standard error of the estimate without the state-by-year interactions (33.0, from Table 4).

An alternative approach to exploring whether our estimates are influenced by other workers’ compensation policy changes that would be expected to influence duration of temporary disability benefits, and could—coincidentally—be correlated with state-by-year changes in opioid prescribing, is to revert to using separate state fixed effects and year fixed effects, but to introduce controls for such policy variation. Specifically, we control for the individual temporary disability benefits replacement rate, and an indicator variable for whether the limits on maximum weekly amount of temporary disability benefits is binding. The estimated effects of opioids prescriptions were nearly identical.

The validity of the instrument depends on there not being unobservables in equation (1) that affect the duration of disability and are correlated with opioids prescribing. The preceding analysis tries to assess this by adding some potential omitted variables. An alternative, indirect approach is to ask whether the 2SLS estimates are sensitive to excluding controls that are plausibly correlated with important unobservables. If the estimates are sensitive, it is because the IV is correlated with the controls, in which case it might be plausible that it is also non-negligibly correlated with the residual. For example, we likely do not measure injury severity perfectly, so sensitivity of the 2SLS estimates to excluding our severity controls might suggest the IV is correlated with unmeasured severity. Table 8 presents OLS and 2SLS estimates of our original specification as well as specifications without controls for injury severity. We also report estimates that instead exclude the controls for location characteristics. The motivation is the same; there could be local labor market differences associated with both duration of disability and with opioids prescribing, and our controls for local labor market conditions may not be perfect. In both cases, however, 
the results are very similar, suggesting there are not important unobservables that bias our IV estimates. Of course, if the injury severity measures were not predictive of the duration of disability, then the fact that excluding them has little influence on the results would not be informative. As noted earlier, however, the severity measures are strongly correlated with this duration, in the expected direction. Similarly, the location-related measures had the expected effects, with significantly longer durations for rural areas and areas where county-level disability rates are higher. ${ }^{43}$

Another concern is that “doctor shopping” generates a correlation between local area prescribing rates and variation across HRRs in worker preferences for opioids. If these preferences are also correlated with duration of temporary disability, this could invalidate our IV. To assess this, we define the IV differently, measuring prescribing rates at the level of prescribers rather than workers. Whereas a workerlevel measure could reflect the sorting of workers with strong preferences for opioids to high-prescribing providers, a provider-level measure could avoid the influence of this sorting. For example, suppose that HRR A and HRR B each have two providers, one of whom prescribes longer-term opioids in 100 percent of cases and the other in 0 percent of cases. Suppose that in HRR A, workers do not have particularly strong preferences for opioids, and cases are split between the two providers, generating a worker-level longer-term opioid percentage of 50. But suppose in HRR B workers all sort to the high provider. In that case, the worker-level measure would be 50 percent in HRR A and 100 percent in HRR B, but the difference reflects only worker sorting. The provider-level measure would be 50 percent in both HRRs, which accurately reflects that provider prescribing is the same in both HRRs.

Thus, to get a measure of provider prescribing behavior that should be less influenced by doctor shopping, we create provider-level measures corresponding to the same measures used earlier, such as the percentage of physicians who prescribed any opioids for low back conditions, the percentage of physicians

\footnotetext{
${ }^{43}$ Our approach is similar in spirit, of course, to regressing these controls on the instruments to see whether there is a relationship, which if there was would raise more concerns about unobservables correlated with the instruments. The insensitivity of the results to excluding either the injury severity controls or the local labor market controls implies that these control variables are not very correlated with opioids prescribing. Also, the evidence from omitting injury control obviates concerns that the injury severity measures we use are based on treatment and diagnosis, which could be endogenous with respect to longer-term opioid prescribing if some physicians, for example, both "over treat" and "over prescribe."
} 
who prescribed at least two opioid prescriptions, etc. To create these measures, we first determine whether a physician/practice prescribed opioids (in the corresponding manner) for each of the workers for whom they wrote prescriptions, and then average these measures across physicians in an area. ${ }^{44}$ As reported in Table 9, using this alternative construction of the IV, the estimated effects of opioid prescribing on the duration of temporary disability are similar to the prior results. The 2SLS estimates still point strongly to much longer durations of temporary disability from longer-term opioid prescriptions.

An alternative IV that addresses the same issue is derived only from the first prescribers that patients visited. A typical case in a sample of low back injuries had five different prescribing physicians and/or practices. Limiting the measurement of local prescribing patterns to only the first prescriber is another way of addressing the concern that aggregate prescribing patterns reflect the impact of patients who want more prescriptions finding providers who are more likely to prescribe opioids due to the nature of the medical services that they provide. As reported in Table 10, the estimates defining the IV this way indicate a similar relationship between opioid prescribing measures and duration of temporary disability to what we found and reported in the earlier tables. These findings, like others reported in subsection, help bolster the validity of our IV estimation strategy.

Yet another potential source of correlation between opioids prescribing and duration of temporary disability benefits is the possibility that events at a single employer (say, a large accident) lead to simultaneous changes in longer-term prescriptions and in duration of disability, but the change in duration is due to the common nature of injuries or slow recovery of jobs at the employer. To explore this possiblity, we deleted observations from the dataset with multiple injuries at the same employer on the same day (approximately 7 percent of observations in the longer-term prescribing sample). This has virtually no impact on the estimates.

Finally, it is possible that longer-term opioids prescribing for low back injuries of the type we study are associated with other treatment differences, and treatment differences, rather than prescribing patterns,

\footnotetext{
${ }^{44}$ For this extension we use billing practice taxpayer identifiers to determine prescriber-level rates. Since practice identifiers are not always available, we limit the sample to claims that have at least 90 percent of prescriptions with practice identifiers. This reduces the sample that we can use to about 27,000 claims. While for many prescriptions this identifies an individual prescriber, for some prescriptions this identifies a practice or even a large hospital.
} 
drive the variation in duration. To assess this, we constructed an alternative opioid prescribing IV—based on non-low back injuries. This IV should be correlated with general opioid prescribing patterns (and indeed the first-stage for opioid prescribing for low back injuries remains strong); but it is less likely to be correlated with other types of variation in treatment for low back injuries, because it is not directly related to treatment of these injuries. Again, this led to similar results.

In our view, this wide variety of analyses meant to assess the validity of the IV we use substantially bolsters the credibility of a causal interpretation of our results. That said, it is not possible to prove that a causal interpretation is valid, and, correspondingly, it is possible to think of other factors that could invalidate the exclusion restriction. One such factor that we cannot get a handle on with our data is physician quality; it is conceivable that this quality varies across HRRs, and that, for example, lower quality physicians both write more longer-term opioid prescriptions and provide worse treatment that lengthens the duration of temporary disability. Second, although our analysis dropping multiple injuries at the same employer on the same day rules out some sources of employer differences that could affect opioid prescribing and duration of disability across HRRs, there could be remaining differences that are not captured in the "multiple events," such as the presence of a large employer in a given HRR that directs a substantial portion of care to a set of providers with common opioid prescribing behavior, and that also has a systematic difference in return to work relative to other employers. Further work that rules out yet more alternatives to a causal interpretation of our results_-perhaps focused on physician behavior or employer behavior—would be useful.

\section{The Impact of Opioid Prescriptions Beyond Low Back Conditions}

We have focused on low back conditions because we can include detailed controls for injury severity and, as noted earlier, the issue of opioid prescribing in such cases is critically important and has been the focus of past research. But what happens if we instead look at all claims (with more than seven days of lost time)? Extending the analysis to all cases requires a different approach to controlling for injury severity, whereas the controls in our analysis of low back injuries were specific to these kinds of injuries. In analyzing all cases with more than seven days of lost time, we must control more coarsely, simply adding controls for injury type. We also define the prescribing-patterns IV to reflect opioid prescriptions within 
each HRR, year, and injury group.

Table 11 reports the results from this broader analysis. We find patterns of results that are similar to what we found for low back injuries. The estimated effect of any opioids prescription is small, and masks differential effects across cases with different numbers of prescriptions. We estimate that the effect of workers having three or more prescriptions (excluding longer-term prescriptions) is to lengthen the duration of temporary disability benefits by 32 percent; the corresponding estimate for low back injuries is not statistically significant. Most important, however, is that the estimated effect for longer-term prescriptions is similar to the earlier estimates for low back cases. The 2SLS estimate indicates that longerterm opioid prescriptions lengthen duration by over 150 percent.

\section{Conclusions}

We provide evidence on the effect of opioid prescriptions on the duration of temporary disability benefits among workers with primarily low back injuries who had more than seven days of lost time after their injuries. We use a research design intended to estimate the causal effect of opioid prescriptions, whereas past studies of opioids and return to work have estimated associations that can reflect a combination of causal effects and unobserved injury severity or other sources of variation in return to work that influence both opioid prescriptions and the duration of disability. Our research strategy uses local opioid prescribing patterns to isolate variation in opioids that is unrelated to characteristics of individual workers, their injuries, and their providers that can affect both opioid prescriptions and return to work. These local prescribing patterns exert a strong influence on whether injured workers receive opioid prescriptions, an interesting finding in itself.

We find that prolonged prescribing of opioids leads to longer duration of temporary disability benefits among workers with work-related low back injuries. Our estimates indicate that longer-term opioid prescriptions roughly triple the duration of temporary disability benefits, compared to similar workers with similar injuries who do not get opioid prescriptions (or do not get longer-term prescriptions). Thus, we clearly do not find evidence, on average, of beneficial effects of opioids prescribed in workers’ compensation cases — benefits that would need to be weighed against the costs of opioid use. 
Our evidence cannot directly address what role opioids play overall in changes in labor force participation. However, our results are consistent with the effects of opioid prescriptions contributing to lower participation by lengthening the time injured workers remain out of work.

These results warrant a more detailed policy focus on longer-term opioid prescriptions. While longer-term prescribing of opioids is not typically recommended for low back pain cases (ACOEM, 2008; Bigos et al., 1994; Chou et al., 2007), it is striking to see that about 12 percent of our sample had longerterm opioids and about 39 percent of workers had at least three opioid prescriptions. Since longer-term opioid prescriptions lead to longer duration of temporary disability benefits, it is important to understand the reasons why workers are receiving opioids on a longer-term basis, so that policy interventions can be targeted toward reducing inappropriate longer-term use.

Note that nothing in our research directly addresses the medical appropriateness of longer-term opioid prescriptions, and indeed in some cases (as some of our evidence suggests), longer-term opioids may enable return to work. But the evidence that workers in areas with higher rates of prescribing longer-term opioids, for similar injuries, have longer disability duration suggests that there is at least some overuse of longer-term opioids that is leading to longer disability duration. We need to understand what generates variation in opioid prescription patterns across geographic areas and what policies could reduce prescription rates in high-prescription areas.

Research has started to provide information on changes in opioid prescribing after policy changes intending to regulate use. These policy changes (and the associated studies) include: a Florida regulation that banned physician dispensing of opioids (Thumula, 2013); Texas regulations implementing a pharmacy closed formulary (TDI, 2013); Kentucky House Bill 1 regulating pain clinics and establishing standards for dispensing and prescribing opioids, including requiring that providers check the state's prescription drug monitoring program before prescribing opioids (Thumula, 2017); and Washington State implementing opioid dosing guidelines for chronic noncancer pain (Franklin et al., 2012; Garg et al., 2013). However, more research is needed in this area, including verifying whether these policy changes reduce longer-term opioid prescribing and, in turn, speed up return to work.

While our analysis captures major dimensions of variation in opioid prescribing, we leave it for 
future research to examine the effects of specific types of opioids or opioid combinations, as well as interactions between opioid prescriptions and use and other care provided. We see no reason such analyses would undermine our broad conclusions, but they could provide more specific guidance regarding how opioids might be used to improve return to work. However, it might be harder to use our identification strategy for estimating the causal effects of opioids on return to work, if more detailed local prescribing and practice patterns are less predictive of individual treatment.

Our results also offer important takeaways for future research linking opioids and outcomes. Our results suggest that simple regressions, even those that account for injury severity, do not reveal the causal effects of opioid prescriptions on outcomes. Even after controlling for observed injury severity, opioid prescribing measures may still be a marker for unobserved dimensions of injury severity or for unobserved worker characteristics related to return-to-work outcomes, in which case empirical associations between opioids and return to work—or other outcomes—may not reflect the actual effects of opioid prescribing. We have proposed an empirical strategy to estimate these causal effects, which we think is compelling. Additional evidence on whether related strategies corroborate our findings would be invaluable. 


\section{References}

Adams, N., M. Plane, M. Fleming, M. Mundt, L. Saunders, and E. Stauffacher. 2001. Opioids and the treatment of chronic pain in a primary care sample. Journal of Pain Symptom Management 22: 791-796.

American College of Occupational and Environmental Medicine (ACOEM). 2008. Practice guidelines chronic pain chapter, revised 2008. Elk Grove Village, Illinois: ACOEM.

Barnett, M., A. Olenski, and A. Jena. 2017. Opioid-prescribing patterns of emergency physicians and risk of long-term use. The New England Journal of Medicine 376: 663-673.

Bigos, S., O. Bowyer, G. Braen, et al. 1994. Acute low back problems in adults. Clinical practice guideline no. 14. AHCPR publication no. 95-0642. Rockville, MD: Agency for Healthcare Policy and Research, Public Health Service, U.S. Department of Health and Human Services.

Bijwaard, G. 2009. Instrumental variable estimation for duration data. In Causal Analysis in Population Studies, H. Engelhardt, H. Kohler, and A. Fürnkranz-Prskawetz, Eds., pp. 114-148. Springer.

Bohnert, A., M. Valenstein, M. Bair, D. Ganoczy, J. McCarthy, M. Ilgen, and F. Blow. 2011. Association between opioid prescribing patterns and opioid overdose-related deaths. Journal of the American Medical Association 305: 1,315-1,321.

Braden, J., J. Russo, M. Fan, M. Edlund, B. Martin, A. DeVries, and M. Sullivan. 2010. Emergency department visits among recipients of chronic opioid therapy. Archives of Internal Medicine 170: $1,425-1,432$.

Chen, L., H. Hedegaard, and M. Warner. 2014. Drug-poisoning deaths involving opioid analgesics: United States, 1999-2011. NCHS Data Brief, 166, September 2014. U.S. Department of Health and Human Services, Centers for Disease Control and Prevention, National Center for Health Statistics.

Chou, R., A. Qaseem, V. Snow, D. Casey, J. Cross, P. Shekelle, and D. Owens. 2007. Diagnosis and treatment of low back pain: A joint clinical practice guideline from the American College of Physicians and the American Pain Society. Annals of Internal Medicine 147: 478-491.

Cifuentes, M., B. Webster, S. Genevay, and G. Pransky. 2010. The course of opioid prescribing for a new episode of disabling low back pain: Opioid features and dose escalation. Pain 151: 22-29.

Coben, J., S. Davis, P. Furbee, R. Sikora, R. Tillotson, and R. Bossarte. 2010. Hospitalizations for poisoning by prescription opioids, sedatives, and tranquilizers. American Journal of Preventive Medicine 38: 517-524.

Dartmouth Institute for Health Policy \& Clinical Practice. 2013a. Zip code to HRR crosswalk, year 2013. Retrieved from http://www.dartmouthatlas.org/downloads/geography/ZipHsaHrr13.xls (accessed September 7, 2017).

. 2013b. Zip code to PCSA crosswalk. Retrieved from http://www.dartmouthatlas.org/downloads/pcsa/zip5_pcsav31.dbf (accessed September 7, 2017).

Dartmouth Medical School. Center for the Evaluative Clinical Sciences. 1999. The Dartmouth Atlas of Health Care 1999. The Center for the Evaluative Clinical Sciences, Dartmouth Medical School. Retrieved from http://www.dartmouthatlas.org/downloads/atlases/99Atlas.pdf (accessed July 17, 2017).

Dave, D., A. Grecu, and H. Saffer. 2017. Mandatory access prescription drug monitoring programs and prescription drug abuse. National Bureau of Economic Research Working Paper 23537. Retrieved from http://www.nber.org/papers/w23537 (accessed July 17, 2017).

Dolinschi, R., and K. Rothkin. 2017. CompScope ${ }^{\mathrm{TM}}$ medical benchmarks: Technical appendix, 18th edition. Cambridge, MA: Workers Compensation Research Institute. 
Dunn K., K. Saunders, C. Rutter, C. Banta-Green, J. Merrill, M. Sullivan, C. Weisner, M. Silverberg, C. Campbell, B. Psaty, and M. Von Korff. 2010. Opioid prescriptions for chronic pain and overdose: A cohort study. Annals of Internal Medicine 152: 85-92.

Faciszewski, T., L. Johnson, C. Noren, M. Smith. 1995. Administrative databases' complication coding in anterior spinal fusion procedures: what does it mean? Spine 20:1783-1788.

Faciszewski T, Broste SK, Fardon D. 1997. Quality of data regarding diagnoses of spinal disorders in administrative databases: a multicenter study. Journal of Bone and Joint Surgery 79:1481-1488.

Faciszewski T, Jensen R, Berg RL. 2003. Procedural coding of spinal surgeries (CPT-4 versus ICD-9CM) and decisions regarding standards: a multicenter study. Spine 28:502-507.

Franklin, G., J. Mai, J. Turner, M. Sullivan, T. Wickizer, and D. Fulton-Kehoe. 2012. Bending the prescription opioid dosing and mortality curves: Impact of the Washington State opioid dosing guideline. American Journal of Industrial Medicine 55: 325-331.

Franklin G., J. Mai, T. Wickizer, J. Turner, D. Fulton-Kehoe, and L. Grant. 2005. Opioid dosing trends and mortality in Washington State workers' compensation, 1996-2002. American Journal of Industrial Medicine 48: 91-99.

Franklin, G., B. Stover, J. Turner, D. Fulton-Kehoe, and T. Wickizer. 2008. Early opioid prescription and subsequent disability among workers with back injuries: The disability risk identification study cohort. Spine 33: 199-204.

Fulton-Kehoe, D., R. Garg, J. Turner, A. Bauer, M. Sullivan, T. Wickizer, and G. Franklin. 2013. Opioid poisonings and opioid adverse effects in workers in Washington State. American Journal of Industrial Medicine 56: 1,452-1,462.

Galizzi, M., and L. Boden. 1996. What are the most important factors shaping return to work? Evidence from Wisconsin. Cambridge, MA: Workers Compensation Research Institute.

Garg, R., D. Fulton-Kehoe, J. Turner, A. Bauer, T. Wickizer, M. Sullivan, and G. Franklin. 2013. Changes in opioid prescribing for Washington workers' compensation claimants after implementation of an opioid dosing guideline for chronic noncancer pain: 2004 to 2010. The Journal of Pain 14: 1,620-1,628.

Gomes, T., M. Mamdani, I. Dhalla, J. Paterson, and D. Juurlink. 2011. Opioid dose and drug-related mortality in patients with nonmalignant pain. Archives of Internal Medicine 171: 686-691.

Gross, D., B. Stephens, Y. Bhambhani, M. Haykowsky, G. Bostick, and S. Rashiq. 2009. Opioid prescriptions in Canadian workers’ compensation claimants. Spine 34: 525-531.

Guller, U. 2006. Surgical outcomes research based on administrative data: inferior or complementary to prospective randomized clinical trials? World Journal of Surgery 30:255-66.

Hill, A. 1965. The Environment and Disease: Association or Causation? Proceedings of the Royal Society of Medicine 58: 295-300.

Kidner, C., T. Mayer, and R. Gatchel. 2009. Higher opioid doses predict poorer functional outcome in patients with chronic disabling occupational musculoskeletal disorders. The Journal of Bone and Joint Surgery 91: 919-927.

Koes, B., M. van Tulder, R. Ostelo, A. Burton, and G. Waddell. 2001. Clinical guidelines for the management of low back pain in primary care: An international comparison. Spine 26: 2,5042,513 .

Krause, N., R. Rugulies, D. Ragland, and S. Syme. 2004. Physical workload, ergonomic problems, and incidence of low back injury: A 7.5-year prospective study of San Francisco transit operators. American Journal of Industrial Medicine 46: 570-585. 
Krueger, Alan B. 2017. Where have all the workers gone? An inquiry into the decline of the U.S. labor force participation rate. Brookings Papers on Economic Activity Fall: 1-59.

Mahmud, M., B. Webster, T. Courtney, S. Matz, J. Tacci, and D. Christiani. 2000. Clinical management and the duration of disability for work-related low back pain. Journal of Occupational and Environmental Medicine 42: 1,178-1,187.

Noble, M., J. Treadwell, S. Tregear, V. Coates, P. Wiffen, C. Akafomo, and K. Schoelles. 2010. Longterm opioid management for chronic noncancer pain. Cochrane Database Syst Rev 20: CD006605.

Paulozzi, L. 2012. Prescription drug overdoses: A review. Journal of Safety Research 43: 283-289.

Paulozzi, L., and J. Annest. 2007. Unintentional poisoning deaths: United States, 1999-2004. Morbidity and Mortality Weekly Report 56: 93-96.

Paulozzi, L., E. Kilbourne, N. Shah, K. Nolte, H. Desai, M. Landen, W. Harvey, and L. Loring. 2012. A history of being prescribed controlled substances and risk of drug overdose death. Pain Medicine 13: 87-95.

Reid, M., L. Engles-Horton, M. Weber, R. Kerns, E. Rogers, and P. O’Connor. 2002. Use of opioid medications for chronic noncancer pain syndromes in primary care. Journal of General Internal Medicine 17: 173-179.

Schnell, M., and J. Currie. 2017. Addressing the opioid epidemic: Is there a role for physician education? American Journal of Health Economics 4: 383-410.

Sengupta, I., M. Baldwin, and V. Reno. 2014. Workers' compensation: Benefits, coverage, and costs, 2012. Washington, D.C.: National Academy of Social Insurance (NASI).

Shraim, M., M. Cifuentes, J. Willetts, H. Marucci-Wellman, and G. Pransky. 2015. Length of disability and medical costs in low back pain: Do state workers' compensation policies make a difference? Journal of Occupational and Environmental Medicine 57: 1,275-1,283.

Swedlow, A., L. Gardner, J. Ireland, and E. Genovese. 2008. Pain management and the use of opioids in the treatment of back conditions in the California workers' compensation system. CWCI Reports to the Industry. Oakland, CA: California Workers' Compensation Institute.

Texas Department of Insurance (TDI), Workers’ Compensation Research and Evaluation Group. 2013. Impact of the Texas pharmacy closed formulary: A preliminary report based on 12-month injuries with 9-month services. Retrieved from http://www.tdi.texas.gov/reports/wcreg/documents/Pharma_070913.pdf (accessed May 29, 2017).

Thumula, V. 2013. Impact of banning physician dispensing of opioids in Florida. Cambridge, MA: Workers Compensation Research Institute. . 2017. Impact of Kentucky opioid reforms. Cambridge, MA: Workers Compensation Research Institute.

Thumula, V., D. Wang, and T. Liu. 2017. Interstate variations in use of opioids, 4th edition. Cambridge, MA: Workers Compensation Research Institute.

U.S. Department of Health and Human Services. 2018. What is the U.S. opioid epidemic? Retrieved from https://www.hhs.gov/opioids/about-the-epidemic/ (accessed September 19, 2018).

Victor, R., O. Fomenko, and J. Gruber. 2015. Will the Affordable Care Act shift claims to workers' compensation payors? Cambridge, MA: Workers Compensation Research Institute.

Volinn, E., J. Fargo, and P. Fine. 2009. Opioid therapy for nonspecific low back pain and the outcome of chronic work loss. Pain 142: 194-201. 
Wang, D. 2017. Longer-term dispensing of opioids, 4th edition. Cambridge, MA: Workers Compensation Research Institute.

Webster, B., M. Cifuentes, S. Verma, and G. Pransky. 2009. Geographic variation in opioid prescribing for acute, work-related, low back pain and associated factors: A multilevel analysis. American Journal of Industrial Medicine 52: 162-171.

Webster, B., S. Verma, and R. Gatchel. 2007. Relationship between early opioid prescribing for acute occupational low back pain and disability duration, medical costs, subsequent surgery and late opioid use. Spine 32: 2,127-2,132.

Yee, C., S. Pizer, and O. Fomenko. 2015. Why surgery rates vary. Cambridge, MA: Workers Compensation Research Institute. 
Figure 1. Distribution of the Average Longer-Term Opioid Prescribing Rates Across States and Hospital Referral within States in Analysis Sample

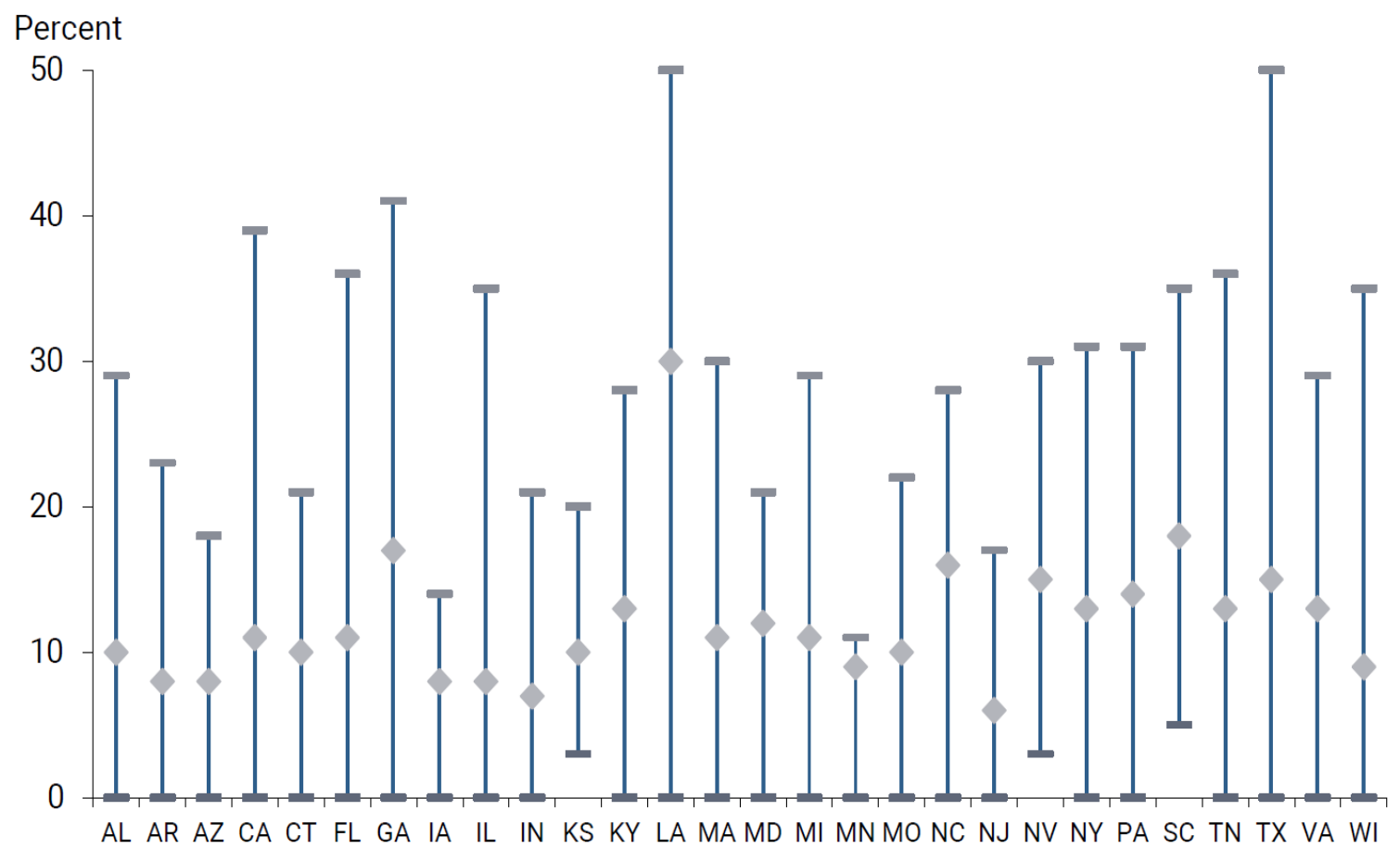

Notes: For each state, the minimum, maximum, and average across HRRs in the state is displayed, averaging across years. Estimates are from a sample of workers with low back injuries between October 1, 2008, and September 30, 2013, across 28 states. 
Table 1. Differences in Duration of Temporary Disability Benefits, and Other Descriptive Statistics, for the Overall Sample and by Opioid Prescribing Measures

\begin{tabular}{|c|c|c|c|c|c|c|c|c|c|}
\hline \multirow[t]{3}{*}{ Variables } & \multirow[b]{2}{*}{$\begin{array}{l}\text { Sample of Low } \\
\text { Back Injuries }\end{array}$} & \multicolumn{2}{|c|}{$\begin{array}{l}\text { Any Opioid } \\
\text { Prescriptions }\end{array}$} & \multicolumn{3}{|c|}{$\begin{array}{c}\text { Number of Opioid } \\
\text { Prescriptions (among those } \\
\text { without longer-term opioid } \\
\text { prescriptions) }\end{array}$} & \multirow{2}{*}{$\begin{array}{l}\text { Longer-Term } \\
\text { Opioid } \\
\text { Prescriptions }\end{array}$} & \multicolumn{2}{|c|}{ Low Back Injuries } \\
\hline & & No & Yes & 1 & 2 & $\begin{array}{l}3 \text { or } \\
\text { More }\end{array}$ & & $\begin{array}{c}\text { With } \\
\text { Surgeries }\end{array}$ & $\begin{array}{c}\text { Without } \\
\text { Surgeries }\end{array}$ \\
\hline & $(1)$ & $(2)$ & (3) & (4) & (5) & $(6)$ & $(7)$ & $(8)$ & (9) \\
\hline \multicolumn{10}{|l|}{ Duration of temporary disability benefits } \\
\hline $\begin{array}{l}\text { Weeks of temporary disability benefit payments } \\
\text { (average) }\end{array}$ & 22.3 & 11.3 & 26.7 & 12.4 & 17.3 & 30.7 & 51.6 & 51.1 & 18.6 \\
\hline $\begin{array}{l}\text { Weeks of temporary disability benefit payments } \\
\text { (median) }\end{array}$ & 9.6 & 4.4 & 13.7 & 4.9 & 8.1 & 19.4 & 49.7 & 47.7 & 7.8 \\
\hline \multicolumn{10}{|l|}{ Opioid variables } \\
\hline $\begin{array}{l}\text { Percentage with any opioid prescriptions within } \\
24 \text { months after an injury }\end{array}$ & $71 \%$ & $0 \%$ & $100 \%$ & $100 \%$ & $100 \%$ & $100 \%$ & $100 \%$ & $95 \%$ & $68 \%$ \\
\hline \multicolumn{10}{|l|}{$\begin{array}{l}\text { Percentage with different numbers of opioid } \\
\text { prescriptions (excluding longer-term opioid } \\
\text { prescriptions) }\end{array}$} \\
\hline None & $29 \%$ & $100 \%$ & $0 \%$ & $0 \%$ & $0 \%$ & $0 \%$ & $0 \%$ & $5 \%$ & $32 \%$ \\
\hline One & $21 \%$ & $0 \%$ & $29 \%$ & $100 \%$ & $0 \%$ & $0 \%$ & $0 \%$ & $8 \%$ & $23 \%$ \\
\hline Two & $11 \%$ & $0 \%$ & $15 \%$ & $0 \%$ & $100 \%$ & $0 \%$ & $0 \%$ & $7 \%$ & $11 \%$ \\
\hline Three or more & $28 \%$ & $0 \%$ & $39 \%$ & $0 \%$ & $0 \%$ & $100 \%$ & $0 \%$ & $47 \%$ & $25 \%$ \\
\hline Percentage with longer-term opioid prescriptions & $12 \%$ & $0 \%$ & $16 \%$ & $0 \%$ & $0 \%$ & $0 \%$ & $100 \%$ & $33 \%$ & $9 \%$ \\
\hline Observations & 32,405 & 9,323 & 23,082 & 6,784 & 3,569 & 8,933 & 3,796 & 3,631 & 28,774 \\
\hline
\end{tabular}

Notes: The sample includes low back injuries with more than seven days of lost time with prescriptions. The data cover workers with primarily low back injuries between October 1, 2008, and September 30, 2013, across 28 states. Claims reflect duration of temporary disability payments within 24 months after an injury.

Longer-term opioid prescriptions are defined as having prescriptions within the first three months after an injury and three or more filled opioid prescriptions between the 7th and 12th months after an injury. The one, two, or three or more prescriptions measures are also based on the period within 24 months after an injury. For the opioid variables, the percentages across the none, one, two, three or more, and longer-term rows add to 100. 
Table 2. Coefficient Estimates from OLS Regression for Duration of Temporary Disability (logged) on “Any Opioid Prescriptions" Variable

\begin{tabular}{|c|c|c|c|c|c|c|c|c|}
\hline \multirow[b]{2}{*}{ Control Variables } & \multicolumn{2}{|c|}{ Specification 1} & \multicolumn{2}{|c|}{ Specification 2} & \multicolumn{2}{|c|}{ Specification 3} & \multicolumn{2}{|c|}{ Specification 4} \\
\hline & Coef. & S.E. & Coef. & S.E. & Coef. & S.E. & Coef. & S.E. \\
\hline $\begin{array}{l}\text { Any opioid prescriptions within } 24 \\
\text { months after an injury }\end{array}$ & $84.8^{* * *}$ & (2.37) & $62.7^{* * *}$ & (2.38) & $36.0^{* * *}$ & $(1.93)$ & $35.7^{* * *}$ & (1.93) \\
\hline Implied percentage effect & $133.5^{* * *}$ & & $87.2^{* * *}$ & & $43.3^{* * *}$ & & $42.9^{* * *}$ & \\
\hline \multicolumn{9}{|c|}{ Injury severity/treatment characteristics } \\
\hline Low back surgery & & & $123.4^{* * *}$ & $(2.00)$ & $166.7^{* * *}$ & $(8.38)$ & $167.5^{* * *}$ & (8.34) \\
\hline Early MRI & & & $39.5^{* * *}$ & $(2.16)$ & $18.3^{* * *}$ & $(1.67)$ & $18.3^{* * *}$ & (1.68) \\
\hline \multicolumn{9}{|l|}{ Severity measures } \\
\hline Surgery severity score & & & & & $12.1^{* * *}$ & $(1.26)$ & $12.0^{* * *}$ & (1.25) \\
\hline \multicolumn{9}{|l|}{ Non-operative severity } \\
\hline \multicolumn{9}{|l|}{ Medications only (base) } \\
\hline Medications and PT only & & & & & $78.3^{* * *}$ & $(2.20)$ & $78.5^{* * *}$ & (2.21) \\
\hline Medications, PT, and injections & & & & & $183.1^{* * *}$ & $(3.15)$ & $183.4^{* * *}$ & (3.17) \\
\hline Observations & 32,405 & & 32,405 & & 32,405 & & 32,405 & \\
\hline R-squared & 0.14 & & 0.25 & & 0.43 & & 0.43 & \\
\hline \multicolumn{9}{|l|}{ Other controls } \\
\hline Worker characteristics & $\mathrm{X}$ & & $\mathrm{X}$ & & $\mathrm{X}$ & & $\mathrm{X}$ & \\
\hline Workplace characteristics & $\mathrm{X}$ & & $\mathrm{X}$ & & $\mathrm{X}$ & & $\mathrm{X}$ & \\
\hline Location characteristics & & & & & & & $\mathrm{X}$ & \\
\hline State and year fixed effects & $\mathrm{X}$ & & $\mathrm{X}$ & & $\mathrm{X}$ & & $\mathrm{X}$ & \\
\hline
\end{tabular}

Notes: The sample includes low back injuries with more than seven days of lost time with prescriptions. The data cover workers with primarily low back injuries between October 1, 2008, and September 30, 2013, across 28 states. Claims reflect duration of temporary disability payments within 24 months after an injury. All specifications include controls for state and year dummies, as well as controls for worker and workplace characteristics (age, gender, marital status, preinjury wage and tenure, and firms' payroll and industry). Specification 2 adds controls for low back surgery and early MRI; specification 3 adds severity controls; and specification 4 adds controls for location characteristics (county unemployment rate, whether a zip code reflects a rural area, percentage of population with less than a high school education at the PCSA level, and percentage of county population who were disabled). The full set of estimates are available upon request. Estimated coefficients and standard errors are multiplied by 100, and hence they should be interpreted as approximate percentage changes.

${ }^{* * *}$ Statistically significant at $1 \%$ level, ${ }^{* *}$ statistically significant at $5 \%$ level, ${ }^{*}$ statistically significant at $10 \%$ level. Standard errors clustered at HRR level.

Key: MRI: magnetic resonance imaging. PCSA: primary care service area. PT: physical therapy. 


\begin{tabular}{|c|c|c|c|c|}
\hline & Observations & Coefficient & S.E. & F-Statistics \\
\hline \multicolumn{5}{|l|}{ Any opioid prescriptions versus no prescriptions } \\
\hline Percentage with any opioid prescriptions at HRR level & 32,405 & $34.2^{* * *}$ & $(3.31)$ & 106.5 \\
\hline R-squared & & 0.13 & & \\
\hline \multicolumn{5}{|l|}{ Two or more opioid prescriptions versus no prescriptions } \\
\hline Percentage with 2 or more opioid prescriptions at HRR level & 24,284 & $35.6^{* * *}$ & $(3.27)$ & 118.5 \\
\hline R-squared & & 0.23 & & \\
\hline \multicolumn{5}{|l|}{ Three or more opioid prescriptions versus no prescriptions } \\
\hline Percentage with 3 or more opioid prescriptions at HRR level & 20,186 & $30.9^{* * *}$ & (3.49) & 78.2 \\
\hline R-squared & & 0.31 & & \\
\hline
\end{tabular}

Two or more opioid prescriptions (excluding longer-term opioid prescriptions) versus no prescriptions

Percentage with 2 or more opioid prescriptions at HRR level $\quad 19,814 \quad 32.3^{* * *}$

$\begin{array}{lr}\text { R-squared } & 0.20\end{array}$

78.1

Three or more opioid prescriptions (excluding longer-term opioid prescriptions) versus no prescriptions

Percentage with 3 or more opioid prescriptions at HRR level $\quad 15,812 \quad 25.6^{* * *}$

$\begin{array}{lr}\text { R-squared } & 0.26\end{array}$

\begin{tabular}{|c|c|c|c|c|}
\hline \multicolumn{5}{|c|}{ Longer-term opioid prescriptions relative to cases with no opioid prescriptions } \\
\hline Percentage with longer-term opioid prescriptions at HRR level & 9,988 & $26.3^{* * *}$ & $(5.13)$ & 26.3 \\
\hline R-squared & & 0.45 & & \\
\hline
\end{tabular}

Notes: The sample includes low back injuries with more than seven days of lost time with prescriptions. The data cover workers with primarily low back injuries between October 1, 2008, and September 30, 2013, across 28 states. Claims reflect duration of temporary disability payments within 24 months after an injury. Estimates are from OLS regressions predicting opioid prescribing measures. Controls are described in notes to Table 2, corresponding to Specification 4 . The local prescribing pattern is measured as a proportion from zero to one, and the dependent variable is either zero or one. Regressions are based on the sample with at least 15 observations within each HRR and year combination for constructing an instrument. See Table 1 and notes for definitions of opioid prescription measures, and Table 2 notes for variable definitions. The full set of estimates for this and all other tables are available upon request.

${ }^{* * *}$ Statistically significant at $1 \%$ level, ${ }^{* *}$ statistically significant at $5 \%$ level, ${ }^{*}$ statistically significant at $10 \%$ level. Standard errors clustered at HRR level.

Key: HRR: hospital referral region. 
Table 4. Estimates from OLS and 2SLS Regressions of Duration of Temporary Disability (logged) on Alternative Measures of Opioid Prescriptions

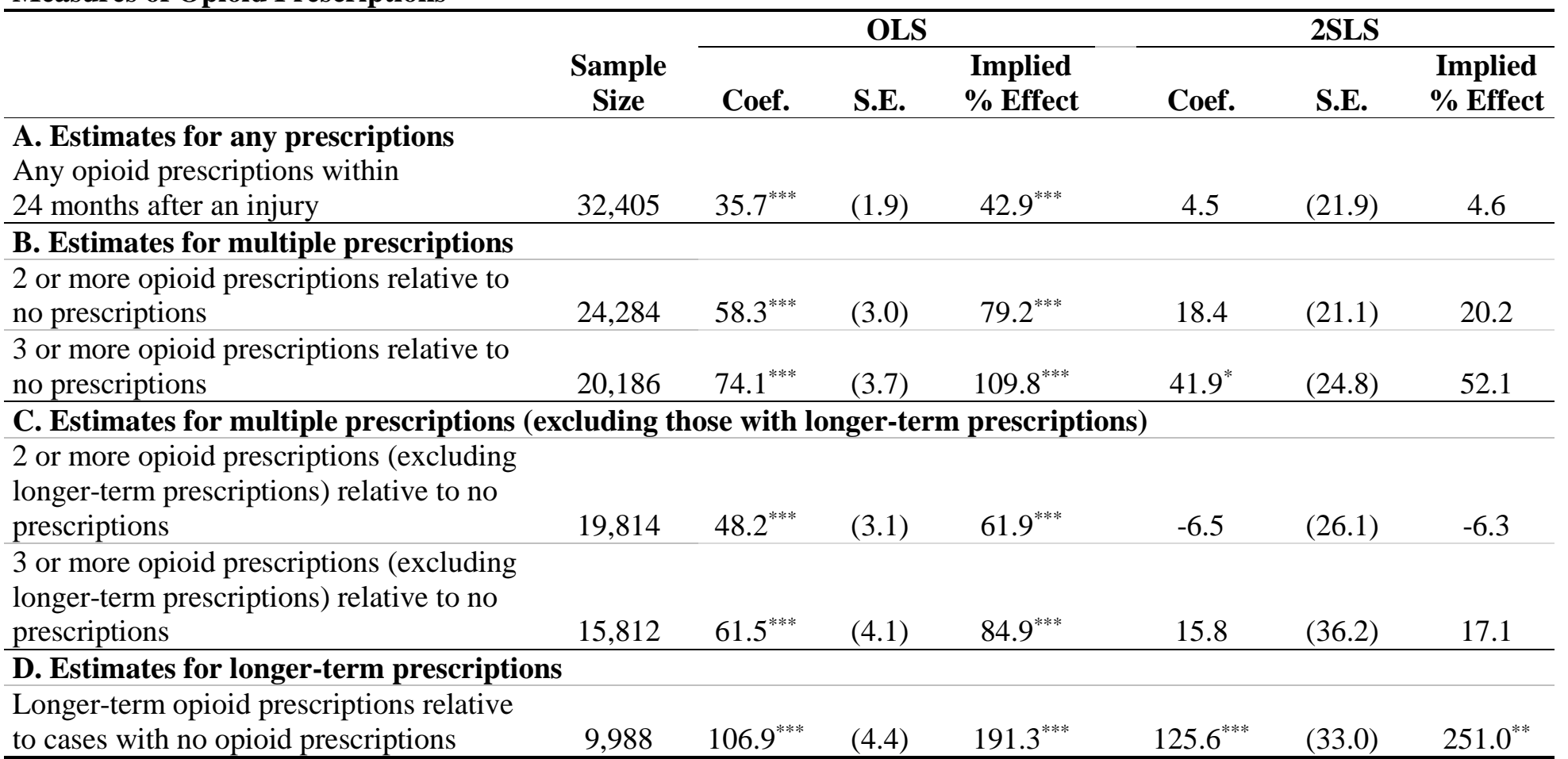

Notes: The sample includes low back injuries with more than seven days of lost time with prescriptions. The data cover workers with primarily low back injuries between October 1, 2008, and September 30, 2013, across 28 states. Claims reflect duration of temporary disability payments within 24 months after an injury. Estimates are from OLS and 2SLS regressions for the indicated measure of opioid prescriptions relative to the base category of "no opioid prescriptions" within 24 months after an injury. Controls are described in notes to Table 2, corresponding to Specification 4. Regressions are based on the sample with at least 15 observations within each HRR and year combination for constructing an instrument. Estimated coefficients and standard errors are multiplied by 100 , and hence they should be interpreted as approximate percentage changes. See Table 1 and notes to Tables 1, 2, and 3 for additional details on variables and sample.

${ }^{* * *}$ Statistically significant at $1 \%$ level, ${ }^{* *}$ statistically significant at $5 \%$ level, ${ }^{*}$ statistically significant at $10 \%$ level. Standard errors clustered at HRR level. 
Table 5. Estimates from OLS and 2SLS Regressions of Duration of Temporary Disability (logged) on Alternative Measures of Opioid Prescriptions, More or Longer-Term Prescriptions Relative to Fewer Prescriptions

\begin{tabular}{|c|c|c|c|c|c|c|c|c|c|}
\hline & \multirow[b]{2}{*}{$\begin{array}{c}\text { Sample } \\
\text { Size }\end{array}$} & \multicolumn{3}{|c|}{ OLS } & \multicolumn{3}{|c|}{ 2SLS } & \multicolumn{2}{|c|}{ First Stage } \\
\hline & & Coef. & S.E. & $\begin{array}{l}\text { Implied \% } \\
\text { Effect }\end{array}$ & Coef. & S.E. & $\begin{array}{l}\text { Implied } \\
\text { \% Effect }\end{array}$ & Coef. & S.E. \\
\hline $\begin{array}{l}\text { A. Estimates for multiple } \\
\text { prescriptions } \\
2 \text { or more opioid prescriptions } \\
\text { relative to } 0 \text { or } 1 \text { prescriptions }\end{array}$ & 32,349 & $56.3^{* * *}$ & (2.5) & $75.6^{* * *}$ & 25.7 & (24.3) & 29.3 & $28.7^{* * *}$ & (3.40) \\
\hline $\begin{array}{l}3 \text { or more opioid prescriptions } \\
\text { relative to } 0,1 \text {, or } 2 \text { prescriptions }\end{array}$ & 32,349 & $65.0^{* * *}$ & $(2.7)$ & $91.6^{* * *}$ & 48.9 & (35.0) & 63.1 & $21.3^{* * *}$ & (3.89) \\
\hline
\end{tabular}

\section{B. Estimates for multiple prescriptions (excluding those with longer-term prescriptions)}

2 or more opioid prescriptions

(excluding longer-term

prescriptions) relative to 0 or 1

prescriptions

$27,74645.8^{* * *}$

$58.1^{* * *}$

$-15.4$

(29.3)

$-14.3$

$25.4^{* * *}$

3 or more opioid prescriptions

(excluding longer-term

prescriptions) relative to 0,1 , or 2

prescriptions

$27,746 \quad 52.8^{* * *}(3.0) \quad 69.5^{* * *}$

$-43.9 \quad(68.7)$

$-35.5$

$13.4^{* * *}$

(4.07)

\section{Estimates for longer-term prescriptions}

Longer-term opioid prescriptions

relative to cases without longer-

term opioid prescriptions

$32,349 \quad 70.1^{* * *} \quad(2.3) \quad 101.6^{* * *}$

$186.6^{* *}(72.9) \quad 546.5$

$17.3^{* * *}(4.48)$

Notes: The sample includes low back injuries with more than seven days of lost time with prescriptions. The data cover workers with primarily low back injuries between October 1, 2008, and September 30, 2013, across 28 states. Claims reflect duration of temporary disability payments within 24 months after an injury. Estimates are from OLS and 2SLS regressions for the indicated measure of opioid prescriptions relative to the base category indicated in each panel within 24 months after an injury, in contrast to the base category of "no opioid prescriptions" used in Table 4. Controls are described in notes to Table 2, corresponding to Specification 4. Estimated coefficients and standard errors are multiplied by 100, and hence they should be interpreted as approximate percentage changes. See Table 1 and notes to Tables 1, 2, and 3 for additional details on variables and sample.

${ }^{* * *}$ Statistically significant at $1 \%$ level, ${ }^{* *}$ statistically significant at $5 \%$ level, ${ }^{*}$ statistically significant at $10 \%$ level. Standard errors clustered at HRR level. 
Table 6. Estimates from OLS and 2SLS Regressions of Duration of Temporary Disability (logged) on Opioid Prescribing Measures for All and for Nonsurgical Cases

\begin{tabular}{|c|c|c|c|c|c|c|c|c|c|}
\hline \multirow[b]{2}{*}{ Specification } & \multirow[b]{2}{*}{ Sample Size } & \multicolumn{3}{|c|}{ OLS } & \multicolumn{3}{|c|}{ 2SLS } & \multicolumn{2}{|c|}{ First Stage } \\
\hline & & Coef. & S.E. & $\begin{array}{c}\text { Implied } \\
\% \text { Effect }\end{array}$ & Coef. & S.E. & $\begin{array}{c}\text { Implied } \\
\% \text { Effect }\end{array}$ & Coef. & S.E. \\
\hline \multicolumn{10}{|c|}{ Any opioid prescriptions within 24 months after an injury } \\
\hline All cases & 32,405 & $35.7^{* * *}$ & $(1.9)$ & $42.9^{* * *}$ & 4.5 & $(21.9)$ & 4.6 & $34.2^{* * *}$ & $(3.3)$ \\
\hline $\begin{array}{l}\text { Nonsurgical } \\
\text { cases }\end{array}$ & 28,108 & $35.8^{* * *}$ & (2.0) & $43.0^{* * *}$ & 12.9 & (23.8) & 13.8 & $32.9^{* * *}$ & (3.9) \\
\hline \multicolumn{10}{|c|}{2 or more opioid prescriptions (excluding longer-term prescriptions) } \\
\hline All cases & 19,814 & $48.2^{* * *}$ & $(3.1)$ & $61.9^{* * *}$ & -6.5 & $(26.1)$ & -6.3 & $32.3^{* * *}$ & $(3.7)$ \\
\hline $\begin{array}{l}\text { Nonsurgical } \\
\text { cases }\end{array}$ & 17,263 & $49.0^{* * *}$ & (3.3) & $63.2^{* * *}$ & -3.5 & $(27.6)$ & -3.4 & $32.7^{* * *}$ & (4.2) \\
\hline \multicolumn{10}{|c|}{3 or more opioid prescriptions (excluding longer-term prescriptions) } \\
\hline All cases & 15,812 & $61.5^{* * *}$ & $(4.1)$ & $84.9^{* * *}$ & 15.8 & $(36.2)$ & 17.1 & $25.6^{* * *}$ & $(4.0)$ \\
\hline $\begin{array}{l}\text { Nonsurgical } \\
\text { cases }\end{array}$ & 13,515 & $63.8^{* * *}$ & $(4.4)$ & $89.3^{* * *}$ & -11.8 & $(36.4)$ & -11.1 & $24.2^{* * *}$ & $(5.0)$ \\
\hline \multicolumn{10}{|c|}{ Longer-term opioid prescriptions } \\
\hline All cases & 9,988 & $106.9^{* * *}$ & $(4.4)$ & $191.3^{* * *}$ & $125.6^{* * *}$ & $(33.0)$ & $251.0^{* *}$ & $26.3^{* * *}$ & $(5.1)$ \\
\hline $\begin{array}{l}\text { Nonsurgical } \\
\text { cases }\end{array}$ & 8,568 & $113.5^{* * *}$ & (4.9) & $211.0^{* * *}$ & $126.6^{* * *}$ & $(39.0)$ & $254.8^{*}$ & $26.5^{* * *}$ & (6.8) \\
\hline
\end{tabular}

Notes: The sample includes low back injuries with more than seven days of lost time with prescriptions. The data cover workers with primarily low back injuries between October 1, 2008, and September 30, 2013, across 28 states. Claims reflect duration of temporary disability payments within 24 months after an injury. Estimates are from OLS and 2SLS regressions for the indicated measure of opioid prescriptions relative to the base category of "no opioid prescriptions" within 24 months after an injury. Controls are described in notes to Table 2, corresponding to Specification 4. Estimated coefficients and standard errors are multiplied by 100, and hence they should be interpreted as approximate percentage changes. See Table 1 and notes to Tables 1, 2, and 3 for additional details on variables and sample.

${ }^{* * *}$ Statistically significant at $1 \%$ level, ${ }^{* *}$ statistically significant at $5 \%$ level, ${ }^{*}$ statistically significant at $10 \%$ level. Standard errors clustered at HRR level. 


\begin{tabular}{|c|c|c|c|c|c|c|}
\hline \multirow[b]{2}{*}{ Specification } & \multirow[b]{2}{*}{$\begin{array}{c}\text { Sample } \\
\text { Size }\end{array}$} & \multicolumn{3}{|c|}{ 2SLS } & \multicolumn{2}{|c|}{ First Stage } \\
\hline & & Coef. & S.E. & $\begin{array}{l}\text { Implied } \\
\text { \% Effect }\end{array}$ & Coef. & S.E. \\
\hline \multicolumn{7}{|l|}{ Any opioid prescriptions } \\
\hline Original specification & 32,405 & 4.5 & $(21.9)$ & 4.6 & $34.2^{* * *}$ & (3.3) \\
\hline With state-year specific fixed effects & 32,405 & -4.7 & $(29.2)$ & -4.6 & $28.2^{* * *}$ & $3.8)$ \\
\hline \multicolumn{7}{|c|}{2 or more opioid prescriptions (excluding longer-term prescriptions) relative to no prescriptions } \\
\hline Original specification & 19,814 & -6.5 & $(26.1)$ & -6.3 & $32.3^{* * *}$ & $(4.0)$ \\
\hline With state-year specific fixed effects & 19,814 & -31.6 & $(35.4)$ & -27.1 & $25.5^{* * *}$ & $(4.9)$ \\
\hline \multicolumn{7}{|c|}{3 or more opioid prescriptions (excluding longer-term prescriptions) relative to no prescriptions } \\
\hline Original specification & 15,812 & 15.8 & $(36.2)$ & 17.1 & $25.6^{* * *}$ & $(4.0)$ \\
\hline With state-year specific fixed effects & 15,812 & -16.8 & $(53.5)$ & -15.5 & $18.9^{* * *}$ & (4.9) \\
\hline \multicolumn{7}{|c|}{ Longer-term opioid prescriptions relative to cases with no opioid prescriptions } \\
\hline Original specification & 9,988 & $125.6^{* * *}$ & $(33.0)$ & $251.0^{* *}$ & $26.3^{* * *}$ & $(5.1)$ \\
\hline With state-year specific fixed effects & 9,988 & $89.9^{*}$ & $(47.7)$ & 145.7 & $18.8^{* * *}$ & $(6.5)$ \\
\hline \multicolumn{7}{|c|}{$\begin{array}{l}\text { Notes: The sample includes low back injuries with more than seven days of lost time with prescriptions. The data } \\
\text { cover workers with primarily low back injuries between October 1, 2008, and September 30, 2013, across } 28 \\
\text { states. Claims reflect duration of temporary disability payments within } 24 \text { months after an injury. Estimates are } \\
\text { from OLS and 2SLS regressions for opioid measures reflecting experience within } 24 \text { months after an injury. } \\
\text { Controls are described in notes to Table 2, and correspond to Specification } 4 \text {, except state-by-year fixed effects are } \\
\text { added. Estimated coefficients and standard errors are multiplied by 100, and hence they should be interpreted as } \\
\text { approximate percentage changes. See Table } 1 \text { and notes to Tables } 1 \text {, 2, and } 3 \text { for additional details on variables and } \\
\text { sample. } \\
\text { Standard errors clustered at HRR level. }\end{array}$} \\
\hline
\end{tabular}




\begin{tabular}{|c|c|c|c|c|}
\hline \multirow[b]{2}{*}{ Specification } & \multirow[b]{2}{*}{ Observations } & \multicolumn{3}{|c|}{ 2SLS } \\
\hline & & Coef. & S.E. & $\begin{array}{c}\text { Implied \% } \\
\text { Effect }\end{array}$ \\
\hline \multicolumn{5}{|l|}{ Any opioid prescriptions } \\
\hline Original specification & 32,405 & 4.5 & $(21.9)$ & 4.6 \\
\hline Specification without controls for injury severity & 5 & 6.3 & 26.7) & 6.5 \\
\hline Specification without controls for location char & & 23.4 & $(18.4)$ & 26.3 \\
\hline \multicolumn{5}{|c|}{2 or more opioid prescriptions (excluding longer-term prescriptions) relative to no prescriptions } \\
\hline Original specification & 19,814 & -6.5 & $(26.1)$ & -6.3 \\
\hline Specification withc & & -7.2 & $(29.7)$ & -6.9 \\
\hline Specification without controls for location characteristics & & 10.1 & $(20.8)$ & 10.6 \\
\hline \multicolumn{5}{|c|}{3 or more opioid prescriptions (excluding longer-term prescriptions) relative to no prescriptions } \\
\hline Original specification & 15,812 & 15.8 & $(36.2)$ & 17.1 \\
\hline Specificat & 2 & 19.1 & $(39.3)$ & 21.0 \\
\hline Specification without controls for location characteristics & 15,812 & 28.8 & $(27.6)$ & 33.4 \\
\hline \multicolumn{5}{|c|}{ Longer-term opioid prescriptions relative to cases with no opioid prescriptions } \\
\hline Original specification & 9,988 & $125.6^{* * *}$ & $(33.0)$ & $251.0^{* *}$ \\
\hline Specification without controls for injury severity & 9,988 & $141.1^{* * *}$ & $(40.0)$ & $309.9^{*}$ \\
\hline Specification without controls for location characteristics & 9,988 & $121.2^{* * *}$ & $(26.2)$ & $236.0^{* * *}$ \\
\hline \multicolumn{5}{|c|}{$\begin{array}{l}\text { Notes: The sample includes low back injuries with more than seven days of lost time with prescriptions. The } \\
\text { data cover workers with primarily low back injuries between October 1, 2008, and September 30, 2013, across } \\
28 \text { states. Claims reflect duration of temporary disability payments within } 24 \text { months after an injury. Estimates } \\
\text { are from OLS and } 2 \text { SLS regressions for opioid measures reflecting experience within } 24 \text { months after an injury. } \\
\text { Controls are described in notes to Table } 2 \text {. Estimated coefficients and standard errors are multiplied by 100, and } \\
\text { hence they should be interpreted as approximate percentage changes. See Table } 1 \text { and notes to Tables } 1,2 \text {, and } \\
3 \text { for additional details on variables and sample. } \\
\text { l** Statistically significant at } 1 \% \text { level, }{ }^{* *} \text { statistically significant at } 5 \% \text { level, }{ }^{*} \text { statistically significant at } 10 \% \\
\text { level. Standard errors clustered at HRR level. }\end{array}$} \\
\hline
\end{tabular}


Table 9. Estimates from Specifications for Alternative Instrument Reflecting Billing Practice Aggregation

\begin{tabular}{|c|c|c|c|c|c|c|c|c|c|}
\hline \multirow[b]{2}{*}{ Specification } & \multirow[b]{2}{*}{$\begin{array}{l}\text { Sample } \\
\text { Size }\end{array}$} & \multicolumn{3}{|c|}{ OLS } & \multicolumn{3}{|c|}{ 2SLS } & \multicolumn{2}{|c|}{ First Stage } \\
\hline & & Coef. & S.E. & $\begin{array}{l}\text { Implied } \\
\text { \% Effect }\end{array}$ & Coef. & S.E. & $\begin{array}{l}\text { Implied } \\
\text { \% Effect }\end{array}$ & Coef. & S.E. \\
\hline \multicolumn{10}{|c|}{$\begin{array}{l}\text { Any opioid prescriptions within } 24 \text { months } \\
\text { after an injury }\end{array}$} \\
\hline $\begin{array}{l}\text { Original instrument, new } \\
\text { subsample }\end{array}$ & 27,420 & $34.4^{* * *}$ & (1.9) & $41.0^{* * *}$ & 12.0 & (22.3) & 12.7 & $36.8^{* * *}$ & (3.4) \\
\hline $\begin{array}{l}\text { Practice level aggregation } \\
\text { for instrument }\end{array}$ & 27,419 & $34.4^{* * *}$ & (1.9) & $41.0^{* * *}$ & 3.3 & (30.7) & 3.4 & $24.8^{* * *}$ & (3.7) \\
\hline \multicolumn{10}{|c|}{$\begin{array}{l}2 \text { or more opioid prescriptions (excluding longer-term prescriptions) relative to no } \\
\text { prescriptions }\end{array}$} \\
\hline $\begin{array}{l}\text { Original instrument, new } \\
\text { subsample }\end{array}$ & 16,724 & $48.1^{* * *}$ & (3.0) & $61.8^{* * *}$ & 1.0 & (27.3) & 1.0 & $34.2^{* * *}$ & (3.9) \\
\hline $\begin{array}{l}\text { Practice level aggregation } \\
\text { for instrument }\end{array}$ & 16,724 & $48.1^{* * *}$ & (3.0) & $61.8^{* * *}$ & 16.4 & (37.8) & 17.8 & $29.6^{* * *}$ & (5.2) \\
\hline \multicolumn{10}{|c|}{$\begin{array}{l}3 \text { or more opioid prescriptions (excluding longer-term prescriptions) relative to no } \\
\text { prescriptions }\end{array}$} \\
\hline $\begin{array}{l}\text { Original instrument, new } \\
\text { subsample }\end{array}$ & 13,338 & $62.4^{* * *}$ & (3.9) & $86.7^{* * *}$ & 13.4 & (37.9) & 14.3 & $27.2^{* * *}$ & (4.2) \\
\hline $\begin{array}{l}\text { Practice level aggregation } \\
\text { for instrument }\end{array}$ & 13,338 & $62.4^{* * *}$ & (3.9) & $86.7^{* * *}$ & -16.9 & $(45.5)$ & -15.5 & $31.0^{* * *}$ & (6.3) \\
\hline
\end{tabular}

Longer-term opioid prescriptions relative to cases with no opioid prescriptions with instrument based on 3 or more prescriptions

Original instrument, new

subsample

$11,412109.2^{* * *}$

$198.1^{* * *} \quad 129.8^{* * *}$

$266.0^{* *} \quad 29.0^{* * *}$

Practice level aggregation

for instrument

$11,411 \quad 109.2^{* * *}$

(4.1) $\quad 198.1^{* * *} \quad 149.5^{* * *} \quad(50.0)$

$345.924 .8^{* * *}$

Notes: The sample includes low back injuries with more than seven days of lost time with prescriptions. The data cover workers with primarily low back injuries between October 1, 2008, and September 30, 2013, across 28 states. Claims reflect duration of temporary disability payments within 24 months after an injury. Estimates are from OLS and 2SLS regressions for opioid measures reflecting experience within 24 months after an injury. Controls are described in notes to Table 2, corresponding to Specification 4. Estimated coefficients and standard errors are multiplied by 100, and hence they should be interpreted as approximate percentage changes. The instrumental variable used in this table differs from other tables; see text. See Table 1 and notes to Tables 1, 2, and 3 for additional details on control variables and sample.

${ }^{* * *}$ Statistically significant at $1 \%$ level, ${ }^{* *}$ statistically significant at $5 \%$ level, ${ }^{*}$ statistically significant at $10 \%$ level. Standard errors clustered at HRR level. 


\begin{tabular}{|c|c|c|c|c|c|c|c|c|c|}
\hline \multirow[b]{2}{*}{ Specification } & \multirow[b]{2}{*}{$\begin{array}{c}\text { Sample } \\
\text { Size }\end{array}$} & \multicolumn{3}{|c|}{ OLS } & \multicolumn{3}{|c|}{ 2SLS } & \multicolumn{2}{|c|}{ First Stage } \\
\hline & & Coef. & S.E. & $\begin{array}{l}\text { Implied } \\
\% \text { Effect }\end{array}$ & Coef. & S.E. & $\begin{array}{l}\text { Implied } \\
\text { \% Effect }\end{array}$ & Coef. & S.E. \\
\hline $\begin{array}{l}\text { Any opioid prescriptions } \\
\text { within } 24 \text { months after an } \\
\text { injury }\end{array}$ & 27,275 & $34.2^{* * *}$ & (1.9) & $40.8^{* * *}$ & 9.6 & (29.3) & 10.1 & $20.8^{* * *}$ & (3.0) \\
\hline $\begin{array}{l}2 \text { or more opioid } \\
\text { prescriptions (excluding } \\
\text { longer-term prescriptions) } \\
\text { relative to no prescriptions }\end{array}$ & 16,653 & $48.1^{* * *}$ & (3.0) & $61.8^{* * *}$ & 22.8 & $(42.2)$ & 25.6 & $21.8^{* * *}$ & (5.0) \\
\hline $\begin{array}{l}\text { Longer-term opioid } \\
\text { prescriptions relative to } \\
\text { cases with no opioid } \\
\text { prescriptions with } \\
\text { instrument based on } 3 \text { or } \\
\text { more prescriptions }\end{array}$ & 11,344 & $109.2^{* * *}$ & (4.1) & $198.1^{* * *}$ & $171.4^{* * *}$ & $(67.4)$ & 455.1 & $15.9^{* * *}$ & (5.1) \\
\hline
\end{tabular}

Notes: The sample includes low back injuries with more than seven days of lost time with prescriptions. The data cover workers with primarily low back injuries between October 1, 2008, and September 30, 2013, across 28 states. Claims reflect duration of temporary disability payments within 24 months after an injury. Estimates are from OLS and 2SLS regressions for opioid measures reflecting experience within 24 months after an injury. Controls are described in notes to Table 2, corresponding to Specification 4. Estimated coefficients and standard errors are multiplied by 100, and hence they should be interpreted as approximate percentage changes. Regressions are based on the sample with at least 30 observations within each HRR for constructing an instrument. The instrumental variable used in this table differs from other tables; see text. See Table 1 and notes to Tables 1, 2, and 3 for additional details on variables and sample.

${ }^{* * *}$ Statistically significant at $1 \%$ level, ${ }^{* *}$ statistically significant at $5 \%$ level, ${ }^{*}$ statistically significant at $10 \%$ level. Standard errors clustered at HRR level. 
Table 11. Estimates from OLS and 2SLS Regressions for Opioid Prescribing Measures for Sample of All Cases with More Than 7 Days of Lost Time

\begin{tabular}{|c|c|c|c|c|c|c|c|c|c|}
\hline \multirow[b]{2}{*}{ Opioid Prescribing Measures } & \multirow[b]{2}{*}{$\begin{array}{c}\text { Sample } \\
\text { Size }\end{array}$} & \multicolumn{3}{|c|}{ OLS } & \multicolumn{3}{|c|}{ 2SLS } & \multicolumn{2}{|c|}{ First Stage } \\
\hline & & Coef. & S.E. & $\begin{array}{l}\text { Implied } \\
\text { \% Effect }\end{array}$ & Coef. & S.E. & $\begin{array}{l}\text { Implied } \\
\text { \% Effect }\end{array}$ & Coef. & S.E. \\
\hline Any opioid prescriptions & 836,875 & $40.8^{* * *}$ & $(1.4)$ & $50.3^{* * *}$ & -13.4 & (15.1) & -12.5 & $53.7^{* * *}$ & $(2.1)$ \\
\hline $\begin{array}{l}2 \text { or more opioid prescriptions } \\
\text { (excluding longer-term } \\
\text { prescriptions) relative to no } \\
\text { opioid prescriptions }\end{array}$ & 554,171 & $56.6^{* * *}$ & (1.9) & $76.2^{* * *}$ & 3.5 & (13.1) & 3.5 & $49.1^{* * *}$ & (2.1) \\
\hline $\begin{array}{l}3 \text { or more opioid prescriptions } \\
\text { (excluding longer-term } \\
\text { prescriptions) relative to no } \\
\text { opioid prescriptions }\end{array}$ & 438,223 & $73.3^{* * *}$ & (2.1) & $108.1^{* * *}$ & $27.7^{* *}$ & (12.9) & $31.9^{*}$ & $44.8^{* * *}$ & $(2.0)$ \\
\hline $\begin{array}{l}\text { Longer-term opioid } \\
\text { prescriptions relative to no } \\
\text { opioid prescriptions }\end{array}$ & 262,945 & $124.3^{* * *}$ & (1.9) & $246.5^{* * *}$ & $94.9^{* * *}$ & $(17.9)$ & $158.4^{* * *}$ & $42.9^{* * *}$ & $(2.2)$ \\
\hline
\end{tabular}

Notes: The sample includes all injuries with more than seven days of lost time with prescriptions. The data cover workers with primarily low back injuries between October 1, 2008, and September 30, 2013, across 28 states. Claims reflect duration of temporary disability payments within 24 months after an injury. Estimates are from OLS and 2SLS regressions for opioid measures reflecting experience within 24 months after an injury. Controls are described in notes to Table 2, corresponding to Specification 4. Estimated coefficients and standard errors are multiplied by 100, and hence they should be interpreted as approximate percentage changes. See Table 1 and notes to Tables 1, 2, and 3 for additional details on variables and sample.

${ }^{* * *}$ Statistically significant at $1 \%$ level, ${ }^{* *}$ statistically significant at $5 \%$ level, ${ }^{*}$ statistically significant at $10 \%$ level. Standard errors clustered at HRR level. 